\title{
Consumer Standards as a Strategic Device to Mitigate Ratchet Effects in Dynamic Regulation
}

\author{
Raffaele Fiocco * \\ Roland Strausz *
}

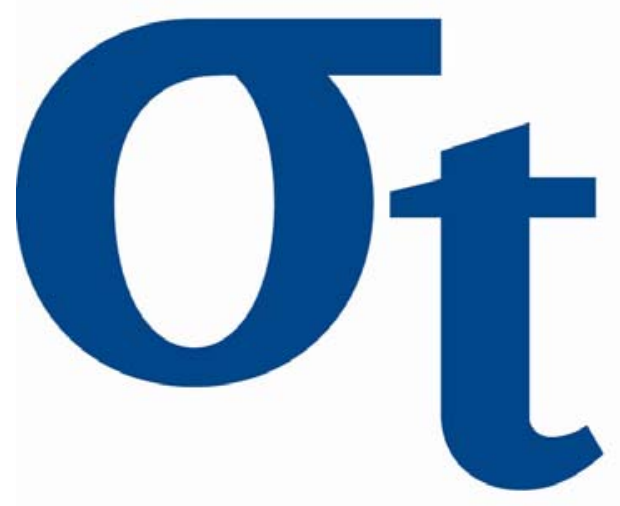

9

$\checkmark$

6

* Humboldt-Universität zu Berlin, Germany 


\title{
Consumer Standards as a Strategic Device to Mitigate Ratchet Effects in Dynamic Regulation
}

\author{
Raffaele Fiocco and Roland Strausz*
}

September 24, 2012

\begin{abstract}
Strategic delegation to an independent regulator with a pure consumer standard improves dynamic regulation by mitigating ratchet effects associated with short term contracting. A consumer standard alleviates the regulator's myopic temptation to raise output after learning the firm is inefficient. Anticipating this tougher regulatory behavior, efficient firms find cost exaggeration less attractive. This reduces the need for long term rents and mitigates ratchet effects. The regulator's welfare standard biased towards consumers comes, however, at the cost of some allocative distortion from the genuine social welfare perspective. Hence, a trade-off results which favors strategic delegation when efficient firms are relatively likely.
\end{abstract}

Keywords: Dynamic regulation, strategic delegation, consumer standard, ratchet effect, limited commitment.

JEL Classification: D82, L51.

\footnotetext{
${ }^{*}$ Humboldt-Universität zu Berlin, Institute for Economic Theory I, Spandauer Str. 1, D-10178 Berlin (Germany), raffaele.fiocco@staff.hu-berlin.de; strauszr@wiwi.hu-berlin.de. We thank Helmut Bester and Mikhail Drugov for helpful discussions and remarks. We also thank the participants at CRESSE Conference in Crete 2012 and CCRP Workshop in Vienna 2012. Financial support by the DFG (German Science Foundation) under SFB649 is gratefully acknowledged.
} 


\section{Introduction}

We investigate the scope for strategic delegation to an independent regulatory agency in a dynamic regulatory framework with ratchet effects due to short term contracting. We show that establishing a regulator with a pure consumer standard, which places more emphasis on the firm's rent extraction than the genuine social welfare function, acts as a strategic device that mitigates ratchet effects. Hence, tougher regulators on firms improve the dynamic efficiency of short term regulatory contracts. In contrast, we do not find any beneficial strategic delegation effect of more lenient regulators.

Our results are consistent with the mandate of modern independent regulatory agencies that focus their attention on consumers, while downplaying the role of profits. For example, Section 2A of the UK Water Industry Act 1991 states that the Water Services Regulation Authority "shall exercise and perform the powers $[\ldots]$ to further the consumer objective", while mentioning with regard to firm profits that the Authority's duty is "to secure that companies [...] are able [...] to finance the proper carrying out of those functions". Consequently, profits are viewed only as an indirect mean for regulators to achieve their primary goal of serving consumers. Similarly, Ofgem, the UK Office of the Gas and Electricity Markets, states that "protecting consumers is our first priority", clarifying further that the "Authority's principal objective is to protect the interests of existing and future consumers". ${ }^{1}$ Likewise, the Federal Energy Regulatory Commission in the US bluntly states on its website: "Mission: Reliable, Efficient and Sustainable Energy for Customers". ${ }^{2}$

Prima facie, the result that a tougher regulator mitigates ratchet effects seems counterintuitive, because economic theory associates the ratchet problem primarily with the inability of decision makers to hand out long term rents. Indeed, this inability suggests that if strategic delegation is beneficial, then only via a regulator that is less inclined to extract rents. This reasoning would lead to the opposite conclusion that regulation should be more lenient towards the firm. Our analysis shows that this intuition is misleading. Rather than restoring the regulator's ability to hand out long term rents, it is preferable to mitigate the ratchet problem by ensuring that the regulator chooses output schedules that reduce the need for long term rents. This leads to the result that tougher regulators improve the dynamics of regulation.

We demonstrate our results in a two-period version of the seminal Baron and Myerson (1982) monopoly regulation model, where a firm has private information about its time invariant marginal costs. A fundamental insight of the Baron and Myerson model is that the firm's private information

\footnotetext{
${ }^{1}$ Quotes with emphasis added are taken directly from Ofgem's website http://www.ofgem.gov.uk.

${ }^{2}$ See http://www.ferc.gov/about/about.asp.
} 
leads the regulator to trade off allocative efficiency against rent extraction. The reason why tougher regulation helps to mitigate ratchet effects is directly related to this fundamental trade-off. Whereas a regulator with full commitment powers can optimally commit to an ex post inefficiently low output of the inefficient firm, a regulator who can only use short term contracts succumbs to the temptation to raise the output of the inefficient firm after learning private information. This myopic regulatory behavior triggers the ratchet problem, since the efficient firm anticipates higher rents from cost exaggeration. A consumer surplus mandate that puts more emphasis on rent extraction alleviates the regulator's myopic temptation to raise output. This reduces the need for long term rents to the efficient firm and thereby mitigates ratchet effects. The benefit comes, however, at the cost of a further output distortion for the inefficient firm, in comparison to the genuine social welfare function. Hence, a trade-off results, which shifts in favor of strategic delegation with the likelihood of the efficient firm. Strategic delegation is therefore optimal when the efficient firm is relatively likely. Otherwise, a regulator with an unbiased welfare perspective is preferable.

A second contribution of our paper is to show that a repeated version of the Baron and Myerson model allows a full characterization of the optimal dynamic regulatory contract in the presence of limited commitment. Laffont and Tirole $(1987,1993)$ emphasize the difficulties in obtaining explicit results within their framework even with two cost types, and they resort to simulations when investigating the ratchet effect. Although the analytical tractability within the Baron and Myerson framework is higher, it still limits us to demonstrate our results with only two cost types. ${ }^{3}$ Nevertheless, the intuition gleaned from the two-type model identifies the general principles underlying our results. Hence, our stylized formulation puts sufficient structure on the problem to derive analytical results, while still being rich enough to describe the relevant effects of short term contracting.

Economic literature has recognized the relevance of strategic delegation for a long time. The seminal papers of Vickers (1985), Fershtman (1985), Fershtman and Judd (1987), and Sklivas (1987) show that a firm's profit-maximizer owner may prefer to distort managerial incentives via a remuneration which is proportional to a (linear) combination of profits and output. More recently, Jansen et al. (2007) find similar results with managerial rewards based on a weighted sum of profits and market share.

Strategic delegation is particularly important in the presence of time inconsistency problems. Rogoff (1985) demonstrates that policy makers can benefit from a central banker whose mandate departs

\footnotetext{
${ }^{3}$ In a Baron and Myerson framework with two types and no commitment, Drugov (2010) also obtains analytical results. Since in his model production takes place at most once, the commitment problem however does not lead to ratchet effects. He points out that tractability is also lost in his setting with a continuum of types (p. 600).
} 
from social welfare and places a too large weight on controlling inflation relative to unemployment. In an environmental regulation framework, Spulber and Besanko (1992) find that a regulatory mandate which assigns a different profit weight from policy makers' preferences is optimal when the agency cannot make a credible commitment to enforce a particular regulatory standard. The direction of distortion crucially depends on whether the actions of the regulator and the firm are profit substitutes or complements. In a companion paper (1993), Besanko and Spulber examine a model of merger policy where the antitrust authority cannot commit to a challenge rule before a merger is proposed. As a result, in the presence of asymmetric information about cost savings from merger, the authority does not internalize the impact that a variation in the challenge rule has on merger self-selection. This yields a more lenient antitrust policy which approves merger proposals with a too high probability. A greater weight on consumer surplus in the welfare standard increases the likelihood of challenge and thereby improves social welfare. ${ }^{4}$

In line with this strand of literature, we investigate strategic delegation as a commitment device to cope with time inconsistency problems. However, differently from previous work, our focus is on the benefits of strategic delegation to mitigate ratchet effects, which the regulation literature considers as a one of the major practical problems in dynamic regulation (e.g., Newbery 1999). Laffont and Tirole (1987, 1988, 1993) clarify that ratchet effects obtain only in the presence of limited commitment. In a two-period version of the Laffont and Tirole (1986) model with time invariant private information, they show that a regulator with full commitment powers finds it optimal to commit not to exploit the information revealed by the firm in earlier periods. If however only short term contracting is feasible, the regulator succumbs to this temptation and therefore a ratchet problem arises. This makes a separating contract more costly, and even unfeasible with a continuum of firm's types. ${ }^{5}$

The rest of the paper is organized as follows. Section 2 sets out the model which allows us to demonstrate our results analytically. Section 3 studies the regulator's behavior for a given regulatory mandate. Section 4 explores the scope for strategic delegation and shows that a pure consumer

\footnotetext{
${ }^{4}$ Baron (1988) shows that if there is a strong electoral connection between the benefits delivered to constituents and their electoral support, the legislature will choose a welfare standard which assigns a greater weight to consumer surplus than firm profits.

${ }^{5}$ Short term contracting is not the only form of limited commitment investigated in the literature on optimal regulation (for a review on this topic, we refer to Armstrong and Sappington 2007). In a companion paper (1990), Laffont and Tirole assume that the regulator can offer the firm a long term contract but both parties may renegotiate the original contract if they agree to do so. Renegotiation presumes that the regulator can credibly promise to deliver future rents to the firm but cannot commit to a specific policy that generates these rents. Baron and Besanko (1987) inquire a different form of limited commitment, labeled as "fairness", which requires the firm to fulfill the terms of future policies if they are "fair" in the light of the information disclosed in earlier periods.
} 
standard is optimal when the efficient firm is relatively likely, otherwise there is no room for strategic delegation. Section 5 concludes. All relevant proofs are relegated to the Appendix.

\section{The model}

We consider a regulated monopolistic firm that can provide a public service with consumer value $S$ in each of two periods $\tau=1,2$. We weight the first period with 1 and the second period with $\rho>1$. The different weighting reflects differences in the length of periods and the number of consumers. ${ }^{6}$

The firm incurs time invariant unit $\operatorname{costs} c_{i}$ for each period it provides the service. With probability $\nu \in(0,1)$ costs are $c_{l}$ and with probability $1-\nu$ costs are $c_{h}$, where $\Delta c \equiv c_{h}-c_{l}>0$. The cost realization is the firm's private information. Fixed costs are normalized to zero. We assume $S>c_{h}$ so that production is also efficient with high costs.

Given a transfer $t_{\tau} \in \mathbb{R}$ and (a probability of) production $q_{\tau} \in[0,1]$ in period $\tau$, the profit of a firm with $\operatorname{costs} c_{i}$ is $\Pi_{\tau i}=t_{\tau}-c_{i} q_{\tau}$, while consumer surplus is $\Psi_{\tau}=S q_{\tau}-t_{\tau}$. We consider a Congress with a social welfare function consisting of a weighted sum of consumer surplus and firm's profits. Congress' objective in period $\tau$ when facing a firm with $\operatorname{costs} c_{i}$ is

$$
W_{\tau i}=\Psi_{\tau}+\alpha_{c} \Pi_{\tau i}=S q_{\tau}-t_{\tau}+\alpha_{c}\left(t_{\tau}-c_{i} q_{\tau}\right)
$$

where $\alpha_{c} \in[0,1]$ is a weight on the firm's profits. Congress' greater concern with consumer surplus than shareholders' rents typically reflects distributional issues or a partial foreign ownership of the firm. Congress' aggregate welfare is the sum over the first and second period:

$$
W_{i}=W_{1 i}+\rho W_{2 i}
$$

In line with the regulation literature, Congress does not engage directly in regulation and thus assigns a regulator the mandate to regulate the firm. The regulator lacks the commitment power to offer the firm a long term regulatory contract that covers both periods. Instead, only short term contracting is feasible. The regulatory mandate is to maximize each period $\tau$ a weighted sum of consumer surplus and firm's profits, which may diverge from Congress' preferences:

$$
V_{\tau i}=\Psi_{\tau}+\alpha_{r} \Pi_{\tau i}=S q_{\tau}-t_{\tau}+\alpha_{r}\left(t_{\tau}-c_{i} q_{\tau}\right),
$$

where $\alpha_{r} \in[0,1]$ is the weight the regulator assigns to profits. ${ }^{7}$

\footnotetext{
${ }^{6}$ We focus on the case $\rho>1$ for expositional reasons. Appendix 2 extends our model to the case $\rho \leq 1$. This complicates the analysis by increasing the number of case distinctions, but does not affect our qualitative results.

${ }^{7}$ Hence, we implicitly assume that, due to practical concerns, the weight $\alpha_{r}$ is time invariant.
} 
Our main question is whether Congress finds it optimal to appoint a regulator with different preferences, namely, with a profit weight $\alpha_{r}$ which diverges from $\alpha_{c}$. The regulator's aggregate payoff is the sum over the first and second period:

$$
V_{i}=V_{1 i}+\rho V_{2 i} .
$$

In summary, we consider the following sequence of events. First, Congress sets the regulatory mandate $\alpha_{r} \in[0,1]$. Second, the firm privately learns its cost type $c_{i} \in\left\{c_{l}, c_{h}\right\}$. Third, the regulator regulates the firm for two periods. In order to distinguish between the three players, we refer to Congress as "she", the regulator as "he", and the firm as "it".

\section{The regulation game}

We start our analysis by considering the regulation game between the regulator and firm for some given weight $\alpha_{r}$. Before solving the dynamic regulatory problem, it is helpful to derive the optimal regulatory schedule for the one-period static problem.

\subsection{Static regulation contracts}

By the revelation principle (e.g., Myerson 1979), the optimal static contract is a direct menu $\left\{\gamma_{l}, \gamma_{h}\right\}=$

$\left\{\left(q_{l}, t_{l}\right),\left(q_{h}, t_{h}\right)\right\}$ that maximizes the regulator's objective under the firm's participation and incentive constraints:

$$
\begin{aligned}
\max _{q_{l}, t_{l}, q_{h}, t_{h}} & \nu\left[S q_{l}-t_{l}+\alpha_{r}\left(t_{l}-c_{l} q_{l}\right)\right]+(1-\nu)\left[S q_{h}-t_{h}+\alpha_{r}\left(t_{h}-c_{h} q_{h}\right)\right] \\
\text { s.t. } & t_{l}-c_{l} q_{l} \geq 0 ; \quad t_{h}-c_{h} q_{h} \geq 0 \\
& t_{l}-c_{l} q_{l} \geq t_{h}-c_{l} q_{h} ; \quad t_{h}-c_{h} q_{h} \geq t_{l}-c_{h} q_{l} .
\end{aligned}
$$

Standard arguments show that the participation constraint of the inefficient firm and the incentive constraint of the efficient firm are binding at the optimal contract. Substituting them out, the problem simplifies to

$$
\max _{q_{l}, q_{h}} \nu\left[\left(S-c_{l}\right) q_{l}-\left(1-\alpha_{r}\right) \Delta c q_{h}\right]+(1-\nu)\left(S-c_{h}\right) q_{h} .
$$

Defining a cutoff value $\bar{\nu}$ as

$$
\bar{\nu} \equiv \frac{S-c_{h}}{S-c_{h}+\left(1-\alpha_{r}\right) \Delta c},
$$

we can fully characterize the optimal static mechanism in the following lemma. 
Lemma 1 (static optimal regulation) The optimal static regulatory policy depends on the likelihood of the efficient firm, $\nu \in(0,1)$, as follows:

i) For $\nu<\bar{\nu}$ it exhibits $\left(q_{l}, t_{l}\right)=\left(q_{h}, t_{h}\right)=\left(1, c_{h}\right)$.

ii) For $\nu \geq \bar{\nu}$ it exhibits $\left(q_{l}, t_{l}\right)=\left(1, c_{l}\right)$ and $\left(q_{h}, t_{h}\right)=(0,0)$.

Underlying the regulation problem is the familiar trade-off between allocative efficiency and rent extraction. For the pessimistic case, $\nu<\bar{\nu}$, where the efficient firm is relatively unlikely, a pooling contract with $q_{l}=q_{h}=1$ is optimal. It ensures an informational rent $\Delta c$ to the efficient firm, and yields the regulator $V_{l}=S-c_{l}-\left(1-\alpha_{r}\right) \Delta c$ when facing costs $c_{l}$ and $V_{h}=S-c_{h}$ when facing costs $c_{h}$. For the optimistic case, $\nu \geq \bar{\nu}$, the optimal mechanism is a separating contract with $q_{l}=1$ and $q_{h}=0$. It leaves no informational rents, and yields the regulator $V_{l}=S-c_{l}$ when facing costs $c_{l}$ and $V_{h}=0$ when facing costs $c_{h}$. Hence, a pooling contract entails an efficient allocation at the cost of informational rents to the efficient firm, which is optimal when this firm's type is relative unlikely. Conversely, a separating contract extracts all informational rents but shuts down the production of the inefficient firm. This is optimal when the efficient firm is relatively likely.

\subsection{Dynamic regulation with long term contracting}

In the two-period regulation problem with full commitment, the revelation principle still applies so that it is optimal for the regulator to offer the firm an incentive compatible menu of two long term contracts $\gamma_{l}=\left\{\left(q_{1 l}, t_{1 l}\right),\left(q_{2 l}, t_{2 l}\right)\right\}$ and $\gamma_{h}=\left\{\left(q_{1 h}, t_{1 h}\right),\left(q_{2 h}, t_{2 h}\right)\right\}$. In principle, each contract might specify different allocations over the two periods. However, it is well established in the literature (Baron and Besanko 1984; Laffont and Tirole 1993) that, with time invariant costs, the regulator's optimal long term contract is a straightforward repetition of the optimal static contract.

Lemma 2 (optimal regulation with long term contracting) The optimal two-period regulatory policy with long term contracting depends on the likelihood of the efficient firm, $\nu \in(0,1)$, as follows:

i) For $\nu<\bar{\nu}$ it exhibits $\left(q_{1 l}, t_{1 l}\right)=\left(q_{1 h}, t_{1 h}\right)=\left(q_{2 l}, t_{2 l}\right)=\left(q_{2 h}, t_{2 h}\right)=\left(1, c_{h}\right)$.

ii) For $\nu \geq \bar{\nu}$ it exhibits $\left(q_{1 l}, t_{1 l}\right)=\left(q_{2 l}, t_{2 l}\right)=\left(1, c_{l}\right)$ and $\left(q_{1 h}, t_{1 h}\right)=\left(q_{2 h}, t_{2 h}\right)=(0,0)$.

\subsection{Dynamic regulation with short term contracting}

We next address the regulation problem when the regulator cannot commit to long term contracts and only short term contracting is feasible. Laffont and Tirole $(1987,1988,1993)$ emphasize that in dynamic regulatory settings with short term contracts, the standard revelation principle does not apply anymore. In particular, the regulator may do better if he uses contracts that do not induce 
the firm to reveal its type truthfully. Bester and Strausz (2001) provide an appropriate adaptation of the revelation principle. They show that, despite a lack of commitment, the mechanism designer still optimally uses a direct mechanism under which truthful revelation is an optimal strategy for the agent but the latter does not necessarily use this strategy with probability one.

For our setup, this means that, in line with the standard revelation principle, we can restrict attention to first period menus where the regulator offers only two contracts $\gamma_{1 l}=\left(q_{1 l}, t_{1 l}\right)$ and $\gamma_{1 h}=\left(q_{1 h}, t_{1 h}\right)$. However, going beyond the standard revelation principle, we also have to consider explicitly the possibility that the firm randomizes between the two contract offers. Of course, in equilibrium, any active randomization must be an optimal behavioral strategy of the firm. Let $\beta_{i}$ be the probability that a firm of type $c_{i}$ picks the contract $\gamma_{1 i}$. By appropriate labeling contracts, we can always ensure that $\beta_{l}+\beta_{h} \geq 1$. Since labeling implies that the type $c_{i}$ is more likely to select the contract $\gamma_{1 i}$ than the other type $c_{j}$, we can interpret $\gamma_{1 i}$ as the contract targeted at $c_{i}$ rather than at $c_{j}$. Moreover, we can focus on pairs $\left(\beta_{l}, \beta_{h}\right)$ with $\beta_{l}>0$ and $\beta_{h}>0 .^{8}$

Given a first period menu $\left\{\gamma_{1 l}, \gamma_{1 h}\right\}$, let $\nu_{2 i} \equiv \operatorname{Pr}\left\{c_{i}=c_{l} \mid \gamma_{1 i}\right\}$ denote the regulator's updated beliefs that the firm's type is $c_{i}$ after the contract $\gamma_{1 i}$ has been chosen in the first period. With these posterior beliefs, the regulator offers the firm a new contract in the second period. This is the final period, and thereby the standard revelation principle applies, which ensures that we can restrict attention to direct incentive compatible mechanisms. Since they may depend on the firm's menu choice in the first period, let $\left\{\gamma_{2 i l}, \gamma_{2 i h}\right\}=\left\{\left(q_{2 i l}, t_{2 i l}\right),\left(q_{2 i h}, t_{2 i h}\right)\right\}$ represent the second period menus which the regulator offers when the firm picked the contract $\gamma_{1 i}$ in the first period.

Hence, the outcome of the regulation game with short term contracting is a first period menu $\left\{\gamma_{1 l}, \gamma_{1 h}\right\}$ and a subsequent tuple

$$
\Gamma=\left\{\left(\beta_{l}, \beta_{h}\right),\left(\nu_{2 l}, \nu_{2 h}\right),\left\{\gamma_{2 l l}, \gamma_{2 l h}\right\},\left\{\gamma_{2 h l}, \gamma_{2 h h}\right\}\right\},
$$

which describes the firm's reporting strategies $\left(\beta_{l}, \beta_{h}\right)$, the regulator's updated beliefs $\left(\nu_{2 l}, \nu_{2 h}\right)$, and the second period menus $\left\{\gamma_{2 l l}, \gamma_{2 l h}\right\}$ and $\left\{\gamma_{2 h l}, \gamma_{2 h h}\right\}$.

Given a first period menu $\left\{\gamma_{1 l}, \gamma_{1 h}\right\}$, the outcome $\Gamma$ constitutes a perfect Bayesian equilibrium $(\mathrm{PBE})$ if

1. (Bayes' consistency) the regulator's updated beliefs $\left(\nu_{2 l}, \nu_{2 h}\right)$ are Bayes' consistent with the firm's reporting strategies $\left(\beta_{l}, \beta_{h}\right)$;

\footnotetext{
${ }^{8}$ This result follows because if $\beta_{i}=0$ then $\beta_{l}+\beta_{h} \geq 1$ implies $\beta_{j}=1$, so that the contract $\gamma_{1 j}$ is picked with probability 1 while $\gamma_{1 i}$ is never picked. This is however equivalent to a menu with $\gamma_{1 i}=\gamma_{1 j}$ and allowing the firm to randomize such that $\beta_{l}+\beta_{h}=1$ with $\beta_{l}>0$ and $\beta_{h}>0$.
} 
2. (sequential rationality) the regulator's second period menus $\left\{\gamma_{2 l l}, \gamma_{2 l h}\right\}$ and $\left\{\gamma_{2 h l}, \gamma_{2 h h}\right\}$ are optimal given his respective beliefs $\nu_{2 l}$ and $\nu_{2 h}$;

3. (optimal reporting) the reporting strategies $\left(\beta_{l}, \beta_{h}\right)$ are optimal given the first period menu $\left\{\gamma_{1 l}, \gamma_{1 h}\right\}$ and the regulator's second period offers $\left\{\gamma_{2 l l}, \gamma_{2 l h}\right\}$ and $\left\{\gamma_{2 h l}, \gamma_{2 h h}\right\}$.

A solution to the regulation game with short term contracting is a first period menu $\left\{\gamma_{1 l}, \gamma_{1 h}\right\}$ along with a PBE outcome $\Gamma$ that maximizes the regulator's objective under the condition that the firm receives non-negative profits. We next discuss the restrictions which these three different equilibrium requirements put on the outcome $\Gamma$.

\section{Bayes' consistency}

Since we can restrict attention to $\beta_{l}>0$ and $\beta_{h}>0$, out-of-equilibrium considerations are irrelevant and Bayes' consistency simply entails

$$
\begin{aligned}
\nu_{h}\left(\beta_{l}, \beta_{h}\right) & \equiv \frac{\nu\left(1-\beta_{l}\right)}{(1-\nu) \beta_{h}+\nu\left(1-\beta_{l}\right)} \\
\nu_{l}\left(\beta_{l}, \beta_{h}\right) & \equiv \frac{\nu \beta_{l}}{(1-\nu)\left(1-\beta_{h}\right)+\nu \beta_{l}} .
\end{aligned}
$$

It follows from $\beta_{l}+\beta_{h} \geq 1$ that $\nu_{h}\left(\beta_{l}, \beta_{h}\right) \leq \nu \leq \nu_{l}\left(\beta_{l}, \beta_{h}\right)$. Hence, Bayes' consistency implies that if the firm selects the contract $\gamma_{1 i}$ in the first period, this raises the regulator's beliefs that the firm is of type $c_{i}$.

\section{Sequential rationality}

The requirement that the second period offer is sequentially rational implies that the menu $\left\{\gamma_{2 i l}, \gamma_{2 i h}\right\}$ must be optimal given the regulator's updated beliefs $\nu_{2 i}$. Consequently, the second period menu coincides with the optimal static mechanism of Lemma 1 with the probability $\nu_{2 i}$ that the firm is efficient.

We know from Lemma 2 that, in the pessimistic case $\nu<\bar{\nu}$, a regulator with full commitment powers finds it optimal to offer a pooling menu for both periods. Since this contract does not affect the regulator's updated beliefs, we obtain the following result.

Lemma 3 (pessimistic case) Suppose $\nu<\bar{\nu}$. Then, a first period full pooling menu $\gamma_{1 l}=\gamma_{1 h}=$ $\left(1, c_{h}\right)$ with reporting strategies $\beta_{l}+\beta_{h}=1$, and a PBE outcome $\Gamma$ with second period full pooling menus $\gamma_{2 l l}=\gamma_{2 l h}=\gamma_{2 h l}=\gamma_{2 h h}=\left(1, c_{h}\right)$ yields the regulator the same payoff as the optimal long term contract and is optimal. 
Conversely, it seems that, in the optimistic case $\nu \geq \bar{\nu}$, short term contracts cannot achieve the optimal outcome under long term contracting. Lemma 2 indicates that in this case the regulator with full commitment powers offers a separating contract for both periods which shuts down the production of the inefficient firm and leaves no rents to the efficient firm. This contracting structure is not sequentially rational, because the firm's private information is fully revealed in the first period and therefore the regulator has an incentive to propose a new second period contract which induces the inefficient firm to produce with a transfer that exactly covers its costs.

Hence, for the optimistic case $\nu \geq \bar{\nu}$, the equilibrium requirements imposed by short term contracting put non-trivial restrictions on the dynamic regulation game. In particular, Bayes' consistency and sequential rationality imply that, in any perfect Bayesian equilibrium, the firm's reporting strategies fully determine the updated beliefs $\nu_{2 i}$ and the second period contract menus $\left\{\gamma_{2 l l}, \gamma_{2 l h}\right\}$ and $\left\{\gamma_{2 h l}, \gamma_{2 h h}\right\}$

Lemma 4 (second period contracts) Suppose $\nu \geq \bar{\nu}$. Then, a PBE outcome $\Gamma$ exhibits $\nu_{2 l}=$ $\nu_{l}\left(\beta_{l}, \beta_{h}\right), \nu_{2 h}=\nu_{h}\left(\beta_{l}, \beta_{h}\right)$, and $\left\{\gamma_{2 l l}, \gamma_{2 l h}\right\}=\left\{\left(1, c_{l}\right),(0,0)\right\}$. Moreover,

i) for $\nu_{h}\left(\beta_{l}, \beta_{h}\right)<\bar{\nu}$ the tuple $\Gamma$ exhibits $\gamma_{2 h l}=\gamma_{2 h h}=\left(1, c_{h}\right)$;

ii) for $\nu_{h}\left(\beta_{l}, \beta_{h}\right) \geq \bar{\nu}$ the tuple $\Gamma$ exhibits $\left\{\gamma_{2 h l}, \gamma_{2 h h}\right\}=\left\{\left(1, c_{l}\right),(0,0)\right\}$.

\section{Optimal reporting}

We next turn to the implications of the final, third requirement that the firm's reporting strategies $\left(\beta_{l}, \beta_{h}\right)$ must be optimal given the first period menu and the second period offers. In the light of Lemma 3, we focus on the non-trivial case $\nu \geq \bar{\nu}$. As Lemma 4 reveals, we have $\gamma_{2 l l}=\left(1, c_{l}\right)$ in any PBE outcome $\Gamma$. Hence, an efficient firm which picks $\gamma_{1 l}$ in the first period exactly breaks even in the second period, and its associated overall payoff is simply $t_{1 l}-c_{l} q_{1 l}$. Conversely, after choosing $\gamma_{1 h}$, an efficient firm receives from $\gamma_{2 h l}$ a second period profit $t_{2 h l}-c_{l} q_{2 h l}$, yielding an overall payoff $t_{1 h}-c_{l} q_{1 h}+\rho\left(t_{2 h l}-c_{l} q_{2 h l}\right)$. For any PBE outcome $\Gamma$, the reporting strategy $\beta_{l}$ is therefore optimal if and only if

$$
\beta_{l}=\arg \max _{\beta \in(0,1]} \beta\left(t_{1 l}-c_{l} q_{1 l}\right)+(1-\beta)\left[t_{1 h}-c_{l} q_{1 h}+\rho\left(t_{2 h l}-c_{l} q_{2 h l}\right)\right] .
$$

Lemma 4 also shows that, in any $\mathrm{PBE}$ outcome $\Gamma$, the inefficient firm does not get any rent in the second period under either $\left\{\gamma_{2 l l}, \gamma_{2 l h}\right\}$ or $\left\{\gamma_{2 h l}, \gamma_{2 h h}\right\}$. Consequently, the reporting strategy $\beta_{h}$ is optimal if and only if

$$
\beta_{h}=\arg \max _{\beta \in(0,1]} \beta\left(t_{1 h}-c_{h} q_{1 h}\right)+(1-\beta)\left(t_{1 l}-c_{h} q_{1 l}\right) .
$$


Conditions (5) and (6) summarize the equilibrium requirements concerning the firm's reporting strategy.

Taking the first-order condition for the maximization problem in (5), it follows that if $\beta_{l}=1$ is optimal, we have

$$
t_{1 l}-c_{l} q_{1 l} \geq t_{1 h}-c_{l} q_{1 h}+\rho\left(t_{2 h l}-c_{l} q_{2 h l}\right) .
$$

This condition characterizes the usual incentive compatibility constraint for the efficient firm, which is induced to report truthfully its costs. If $\beta_{l} \in(0,1)$, then (5) implies that $(7)$ must hold with equality.

Similarly, it follows from (6) that if $\beta_{h}=1$ is optimal, we have

$$
t_{1 h}-c_{h} q_{1 h} \geq t_{1 l}-c_{h} q_{1 l}
$$

which represents the standard incentive compatibility condition for the inefficient firm. If $\beta_{h} \in(0,1)$, then (6) implies that (8) must be satisfied with equality.

The next lemma shows how optimal reporting and sequential rationality place limits on any PBE outcome $\Gamma$.

Lemma 5 (information revelation) Suppose $\nu \geq \bar{\nu}$. Then, in any PBE outcome $\Gamma$, it holds $\nu_{h}\left(\beta_{l}, \beta_{h}\right) \geq \bar{\nu}$. Equivalently, in any PBE outcome $\Gamma$, the reporting strategies $\left(\beta_{l}, \beta_{h}\right)$ are such that $\beta_{l} \leq \bar{\beta}_{l}\left(\beta_{h}\right)$, where

$$
\bar{\beta}_{l}\left(\beta_{h}\right) \equiv 1-\frac{(1-\nu)\left(S-c_{h}\right)}{\left(1-\alpha_{r}\right) \nu \Delta c} \beta_{h} \in(0,1) .
$$

Lemma 5 shows that, in the optimistic case $\nu \geq \bar{\nu}$, the regulator cannot induce too much information revelation. In particular, it is not feasible to achieve full revelation, i.e., $\beta_{l}=\beta_{h}=1$, because $\bar{\beta}_{l}(1)<1$. This result is a consequence of the well-known "take-the-money-and-run" strategy (Laffont and Tirole 1993). The intuition is that an efficient firm anticipating the ratchet problem requires a large upfront payment in order to induce it to reveal itself in the first period. This payment makes it however attractive to the inefficient firm to claim it is efficient. When the second period is sufficiently valuable $(\rho>1)$ so that the upfront payment is relatively large, the regulator that wants to induce full information revelation cannot resolve the conflict between the two incentive problems; the two incentive constraints (7) and (8) are mutually inconsistent.

Laffont and Tirole $(1987,1993)$ show that, in a dynamic regulatory framework which builds on Laffont and Tirole (1986) with short term contracting, it is hard to get analytical solutions even in two-type models. Therefore, they resort to numerical simulations to illustrate possible results. One of our contributions is to show that a dynamic regulation model à la Baron and Myerson (1982) 
puts enough structure on the problem to obtain analytical solutions, while still being rich enough to illustrate the relevant effects of short term contracting.

For the optimistic case $\nu \geq \bar{\nu}$, Lemma 5 ensures that we can restrict attention to $\nu_{2 h}=\nu_{h}\left(\beta_{l}, \beta_{h}\right) \geq$ $\bar{\nu}$. Because $\nu_{2 l}=\nu_{l}\left(\beta_{l}, \beta_{h}\right) \geq \nu \geq \bar{\nu}$, Lemma 4 and the discussion following Lemma 1 imply that the regulator's aggregate (expected) payoff in (2) for a first period menu $\left\{\gamma_{1 l}, \gamma_{1 h}\right\}$ and a PBE outcome $\Gamma$, can be written as

$$
\begin{aligned}
V= & \nu\left\{\beta_{l}\left[S q_{1 l}-t_{1 l}+\alpha_{r}\left(t_{1 l}-c_{l} q_{1 l}\right)\right]+\left(1-\beta_{l}\right)\left[S q_{1 h}-t_{1 h}+\alpha_{r}\left(t_{1 h}-c_{l} q_{1 h}\right)\right]+\rho\left(S-c_{l}\right)\right\} \\
& +(1-\nu)\left\{\beta_{h}\left[S q_{1 h}-t_{1 h}+\alpha_{r}\left(t_{1 h}-c_{h} q_{1 h}\right)\right]+\left(1-\beta_{h}\right)\left[S q_{1 l}-t_{1 l}+\alpha_{r}\left(t_{1 l}-c_{h} q_{1 l}\right)\right]\right\} .
\end{aligned}
$$

In order to induce the firm's participation, overall profits from the regulatory relationship must be non-negative. We know from Lemma 4 that for $\nu_{2 l} \geq \bar{\nu}$ and $\nu_{2 h} \geq \bar{\nu}$ the efficient firm does not get any rent in the second period, so that its participation constraint reduces to

$$
\beta_{l}\left(t_{1 l}-c_{l} q_{1 l}\right)+\left(1-\beta_{l}\right)\left(t_{1 h}-c_{l} q_{1 h}\right) \geq 0
$$

Likewise, the participation constraint of the inefficient firm is

$$
\beta_{h}\left(t_{1 h}-c_{h} q_{1 h}\right)+\left(1-\beta_{h}\right)\left(t_{1 l}-c_{h} q_{1 l}\right) \geq 0 .
$$

Hence, for the optimistic case $\nu \geq \bar{\nu}$, the regulator solves

$$
P^{o}: \max _{\beta_{l}, \beta_{h}, q_{1 l}, q_{1 h}, t_{1 l}, t_{1 h}} V \text { s.t. (5), (6), (10), (11), }
$$

under the domain restriction $\beta_{l} \leq \bar{\beta}_{l}\left(\beta_{h}\right)$.

The additional domain restriction in problem $P^{o}$ reflects the regulator's inability to fully separate types in the first period. We know from Lemma 5 that the efficient firm can pick "its" contract $\gamma_{1 l}$ at most with probability $\bar{\beta}_{l}\left(\beta_{h}\right) \in(0,1)$ when the inefficient firm picks "its" contract $\gamma_{1 h}$ with probability $\beta_{h}$. Hence, full information revelation cannot be achieved and only partial separation is feasible, which implies some misallocation of types to contracts in the first period. This observation suggests that short term contracting increases the cutoff level above which the regulator no longer pools types in the first period. Moreover, when partial separation is implemented, it seems natural to induce the highest degree of information revelation, i.e., $\beta_{l}=\bar{\beta}_{l}(1)$ and $\beta_{h}=1$, since this increases allocative efficiency at no cost in terms of informational rents.

Defining the cutoff level

$$
\tilde{\nu} \equiv \frac{\left(S-c_{h}\right)\left(S-c_{l}+\left(1-\alpha_{r}\right) \Delta c\right)}{\left(S-c_{h}\right)\left(S-c_{l}+\left(1-\alpha_{r}\right) \Delta c\right)+\left(1-\alpha_{r}\right)^{2}(\Delta c)^{2}} \in(\bar{\nu}, 1),
$$


the following lemma corroborates the two aforementioned insights formally. ${ }^{9}$

Lemma 6 (optimistic case) Suppose $\nu \geq \bar{\nu}$. Then, a solution to the regulation problem with short term contracting, $P^{o}$, depends on the likelihood of the efficient firm, $\nu \in(0,1)$, as follows:

(i) For $\nu<\tilde{\nu}$ it consists of a first period full pooling menu $\gamma_{1 l}=\gamma_{1 h}=\left(1, c_{h}\right)$ with reporting strategies $\beta_{l}+\beta_{h}=1$, and a PBE outcome $\Gamma$ with second period full separation menus $\left\{\gamma_{2 l l}, \gamma_{2 l h}\right\}=$ $\left\{\gamma_{2 h l}, \gamma_{2 h h}\right\}=\left\{\left(1, c_{l}\right),(0,0)\right\}$.

(ii) For $\nu \geq \tilde{\nu}$ it consists of a first period partial separation menu $\left\{\gamma_{1 l}, \gamma_{1 h}\right\}=\left\{\left(1, c_{l}\right),(0,0)\right\}$ with reporting strategies $\beta_{l}=\bar{\beta}_{l}(1)$ and $\beta_{h}=1$, and a PBE outcome $\Gamma$ with full separation menus $\left\{\gamma_{2 l l}, \gamma_{2 l h}\right\}=\left\{\gamma_{2 h l}, \gamma_{2 h h}\right\}=\left\{\left(1, c_{l}\right),(0,0)\right\}$

Equipped with the results of Lemma 3 and Lemma 6 we are finally able to fully characterize the solution to the regulation problem with short term contracting.

Proposition 1 (optimal regulation with short term contracting) The optimal two-period regulatory policy with short term contracting depends on the likelihood of the efficient firm, $\nu \in(0,1)$, as follows:

(i) For $\nu<\bar{\nu}$ it coincides with the solution under long term contracting and consists of a first period full pooling menu $\gamma_{1 l}=\gamma_{1 h}=\left(1, c_{h}\right)$ with reporting strategies $\beta_{l}+\beta_{h}=1$, and a PBE outcome $\Gamma$ with full pooling menus $\gamma_{2 l l}=\gamma_{2 l h}=\gamma_{2 h l}=\gamma_{2 h h}=\left(1, c_{h}\right)$.

(ii) For $\nu \in[\bar{\nu}, \tilde{\nu})$ it consists of a first period full pooling menu $\gamma_{1 l}=\gamma_{1 h}=\left(1, c_{h}\right)$ with reporting strategies $\beta_{l}+\beta_{h}=1$, and a PBE outcome $\Gamma$ with full separation menus $\left\{\gamma_{2 l l}, \gamma_{2 l h}\right\}=\left\{\gamma_{2 h l}, \gamma_{2 h h}\right\}=$ $\left\{\left(1, c_{l}\right),(0,0)\right\}$.

(iii) For $\nu \geq \tilde{\nu}$ it consists of a first period partial separation menu $\left\{\gamma_{1 l}, \gamma_{1 h}\right\}=\left\{\left(1, c_{l}\right),(0,0)\right\}$ with reporting strategies $\beta_{l}=\bar{\beta}_{l}(1)$ and $\beta_{h}=1$, and a PBE outcome $\Gamma$ with full separation menus $\left\{\gamma_{2 l l}, \gamma_{2 l h}\right\}=\left\{\gamma_{2 h l}, \gamma_{2 h h}\right\}=\left\{\left(1, c_{l}\right),(0,0)\right\}$

The discussion following Lemma 5 emphasizes that, for the optimistic case $\nu \geq \bar{\nu}$, the ratchet effect prevents the regulator from achieving full information revelation in the first period. Proposition 1 indicates that the regulator has two options to cope with this problem. Either he refrains from offering a revelation contract in the first period altogether, or he designs a partial separation contract that still induces some information revelation. The advantage of the pooling contract is that it ensures production in the first period, whereas partial separation allows the regulator to save rents

${ }^{9}$ Note that $\tilde{\nu}=\frac{\left(S-c_{h}\right)\left(S-c_{l}+\left(1-\alpha_{r}\right) \Delta c\right)}{\left(S-c_{h}\right)\left(S-c_{l}+\left(1-\alpha_{r}\right) \Delta c\right)+\left(1-\alpha_{r}\right)^{2}(\Delta c)^{2}}=\frac{\left(S-c_{h}\right)\left(S-c_{l}+\left(1-\alpha_{r}\right) \Delta c\right)}{\left(S-c_{h}\right)\left(S-c_{l}\right)+\left(S-c_{h}+\left(1-\alpha_{r}\right) \Delta c\right)\left(1-\alpha_{r}\right) \Delta c} \quad=\quad \frac{\left(S-c_{h}\right)\left(S-c_{l}+\left(1-\alpha_{r}\right) \Delta c\right)}{\left(S-c_{h}+\left(1-\alpha_{r}\right) \Delta c\right)\left(S-c_{l}+\left(1-\alpha_{r}\right) \Delta c\right)}=\frac{\left(S-c_{h}\right)}{\left(S-c_{h}+\left(1-\alpha_{r}\right) \Delta c\right)}=\bar{\nu}$.


to the efficient firm. Clearly, the second option is only attractive when the efficient firm is relatively likely. Proposition 1 reflects this intuition and shows that a first period partial separation contract is preferable if the probability of an efficient firm is sufficiently high.

\section{Optimal strategic delegation}

We are now in a position to investigate whether Congress benefits from strategic delegation by assigning the regulator a mandate with a profit weight $\alpha_{r}$ that differs from her own weight $\alpha_{c}$. The following proposition shows that there is no gain from strategic delegation as long as the regulator can commit to long term contracts. This intuitive result emphasizes that any benefit of strategic delegation in the regulation problem with short term contracting is indeed due to a lack of commitment to long term contracts.

Proposition 2 Under long term contracting there is no value from strategic delegation and Congress finds it optimal to set a regulatory weight on profits $\alpha_{r}=\alpha_{c}$.

We next examine the scope for strategic delegation under short term contracting. A direct implication of Proposition 2 is that strategic delegation is potentially valuable for $\nu \geq \bar{\nu}\left(\alpha_{c}\right)$. Indeed, we know from Lemma 3 that for $\nu<\bar{\nu}\left(\alpha_{c}\right)$ short term contracts achieve the same outcome as under long term contracting, and therefore strategic delegation cannot be helpful.

Note from Proposition 1 that the regulatory outcome - and thereby Congress' payoff - crucially depends on the weight $\alpha_{r}$ via the two cutoff values $\bar{\nu}$ and $\tilde{\nu}$ that determine how the regulator optimally trades off allocative efficiency against rent extraction. In addition, the weight $\alpha_{r}$ affects the reporting probability $\bar{\beta}_{l}(1)$ under partial separation. In order to express this dependence more explicitly, we write $\bar{\nu}\left(\alpha_{r}\right), \tilde{\nu}\left(\alpha_{r}\right)$, and $\hat{\beta}_{l}\left(\alpha_{r}\right)$, where

$$
\hat{\beta}_{l}\left(\alpha_{r}\right) \equiv \bar{\beta}_{l}(1)=1-\frac{(1-\nu)\left(S-c_{h}\right)}{\left(1-\alpha_{r}\right) \nu \Delta c} .
$$

Using the results in Proposition 1, Congress' aggregate (expected) payoff in (1) can be represented as a function of the regulatory weight $\alpha_{r}$ in the following way:

$$
W\left(\alpha_{r}\right)= \begin{cases}W^{f c} \equiv(1+\rho)\left(S-c_{h}+\nu \alpha_{c} \Delta c\right) & \text { if } \nu<\bar{\nu}\left(\alpha_{r}\right) \\ W^{p} \equiv S-c_{h}+\nu \alpha_{c} \Delta c+\nu \rho\left(S-c_{l}\right) & \text { if } \nu \in\left[\bar{\nu}\left(\alpha_{r}\right), \tilde{\nu}\left(\alpha_{r}\right)\right) \\ W^{p s}\left(\alpha_{r}\right) \equiv \nu\left(S-c_{l}\right)\left(\hat{\beta}_{l}\left(\alpha_{r}\right)+\rho\right) & \text { if } \nu \geq \tilde{\nu}\left(\alpha_{r}\right) .\end{cases}
$$

Defining

$$
\nu^{*}\left(\alpha_{c}\right) \equiv \frac{\left(S-c_{h}\right)\left(S-c_{l}+\Delta c\right)}{\left(S-c_{h}\right)\left(S-c_{l}+\Delta c\right)+\left(1-\alpha_{c}\right)(\Delta c)^{2}} \in\left(\bar{\nu}\left(\alpha_{c}\right), 1\right)
$$


enables us to present our main result. ${ }^{10}$

Proposition 3 (optimal delegation) For $\nu>\nu^{*}\left(\alpha_{c}\right)$, Congress strictly benefits from strategic delegation. Optimal delegation assigns the regulator a profit weight $\alpha_{r}=0$, i.e., a pure consumer standard. For $\nu \leq \nu^{*}\left(\alpha_{c}\right)$, Congress does not benefit from strategic delegation and finds it optimal to set a weight $\alpha_{r}=\alpha_{c}$, implying a regulator with an unbiased welfare perspective.

Proposition 3 shows that if strategic delegation is beneficial, then it induces the regulator to be tougher on the firm by assigning him a pure consumer standard. In order to understand the intuition behind this result, it is helpful to reconsider the logic why ratchet effects are actually problematic. We know from Lemma 2 that for $\nu \geq \bar{\nu}$ a regulator with full commitment optimally commits to an ex post inefficiently low output of the inefficient firm in order to reduce the (relatively costly) rents to the efficient firm. This regulatory behavior is however not feasible with short term contracting. Once a myopic regulator has learned that the firm is inefficient, he finds it no longer optimal to distort its production downwards. It is exactly this myopic reaction that triggers the ratchet problem, because the efficient firm anticipates that it would receive a higher rent in the second period if it claims to be inefficient in the first. If the regulator did not succumb to the temptation to raise the inefficient firm's output, then the efficient firm would not require a higher rent for revealing its information and the problems associated with the rachet effect would not arise. This insight clarifies that a crucial driver of the ratchet problem is the regulator's temptation to raise the firm's output after learning it is inefficient. A pure consumer standard, which places more emphasis on rent extraction, alleviates this temptation. It reduces the need for long term rents to the efficient firm and thereby mitigates the ratchet effect. ${ }^{11}$ In comparison to Congress' (weighted) welfare perspective, a consumer standard comes, however, at the allocative cost of a further reduction in the inefficient firm's production. An additional cost follows from some misallocation of firm's types to contracts in equilibrium. As a result, Congress faces a cost-benefit trade-off when delegating regulation. Since this trade-off shifts in favor of strategic delegation with the likelihood of the efficient firm, strategic delegation is optimal when the efficient firm is relatively likely. ${ }^{12}$ Conversely, when the efficient firm is relatively unlikely,

\footnotetext{
${ }^{10}$ Note $\quad \nu^{*}\left(\alpha_{c}\right) \quad=\quad \frac{\left(S-c_{h}\right)\left(S-c_{l}+\Delta c\right)}{\left(S-c_{h}\right)\left(S-c_{l}+\Delta c\right)+\left(1-\alpha_{c}\right)(\Delta c)^{2}} \quad=\quad \frac{\left(S-c_{h}\right)\left(S-c_{l}+\Delta c\right)}{\left(S-c_{h}\right)\left(S-c_{l}\right)+\left(S-c_{h}+\left(1-\alpha_{c}\right) \Delta c\right) \Delta c}$ $\frac{\left(S-c_{h}\right)\left(S-c_{l}+\Delta c\right)}{\left(S-c_{h}+\left(1-\alpha_{c}\right) \Delta c\right)\left(S-c_{l}\right)+\left(S-c_{h}+\left(1-\alpha_{c}\right) \Delta c\right) \Delta c}=\frac{\left(S-c_{h}\right)\left(S-c_{l}+\Delta c\right)}{\left(S-c_{h}+\left(1-\alpha_{c}\right) \Delta c\right)\left(S-c_{l}+\Delta c\right)}=\frac{\left(S-c_{h}\right)}{S-c_{h}+\left(1-\alpha_{c}\right) \Delta c}=\bar{\nu}\left(\alpha_{c}\right)$.

${ }^{11}$ Referring to Proposition 1, one may establish this effect formally by noting that the cutoff $\tilde{\nu}$, below which the regulator raises the output of the contract $\gamma_{1 h}$, is increasing in $\alpha_{r}$. Hence, the beneficial effect of a lower $\alpha_{r}$ is to allow a larger degree of separation, while keeping the efficient firm's long term rents at zero.

${ }^{12} \mathrm{~A}$ consumer standard facilitates separation between firm's types at the cost that the efficient firm picks the distorted contract $\gamma_{1 h}$ with a positive probability $1-\widehat{\beta}_{l}(0)$ which decreases in $\nu$, due to $\partial \widehat{\beta}_{l}(0) / \partial \nu>0$.
} 


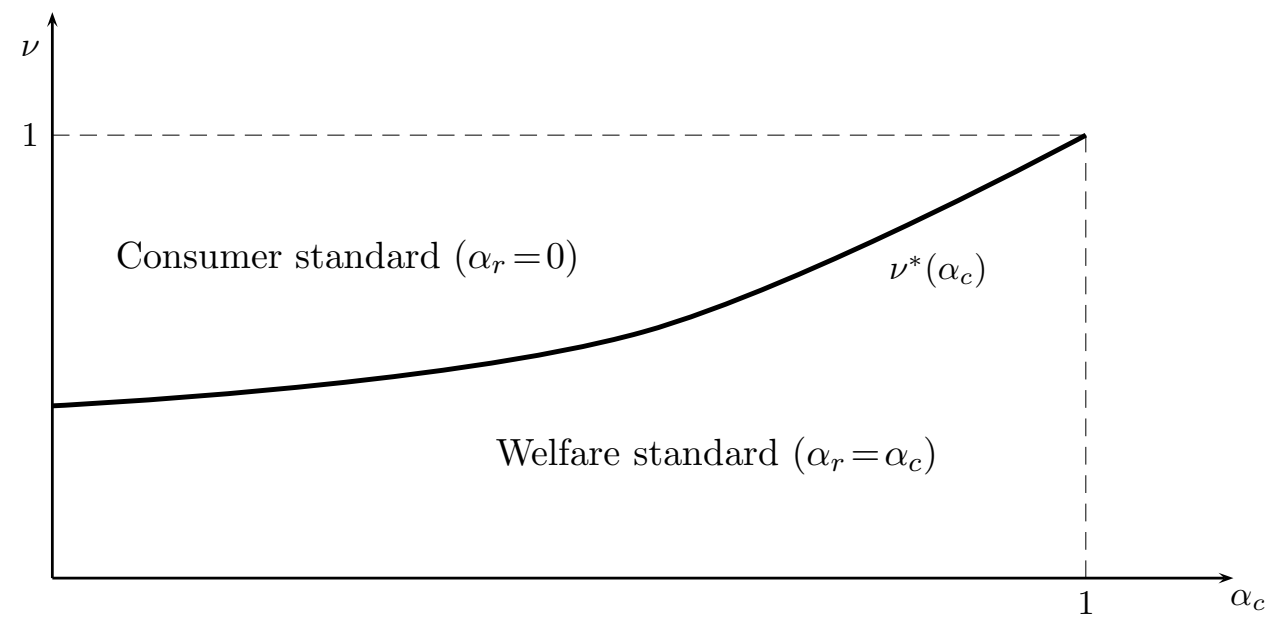

Figure 1: Optimal strategic delegation

the allocative cost of distorting production is too high and a regulator with an unbiased welfare perspective is preferable.

The proposition further shows that strategic delegation with a more lenient mandate, which assigns a greater weight on profits than Congress' preferences, is never optimal. In the light of the usual intuition that the problem behind the ratchet effect is driven by the regulator's inability to resist expropriating rents after learning new information, this conclusion seems surprising because a more lenient regulator is indeed less eager to extract rents. Yet, a more lenient regulator is less inclined to distort the output of the inefficient firm. We find from Lemma 2 that for $\nu \geq \bar{\nu}\left(\alpha_{c}\right)$, where strategic delegation is potentially helpful, this is exactly the opposite of what a regulator with full commitment powers would do. A more lenient mandate therefore aggravates rather than mitigates the ratchet effect.

As Figure 1 illustrates, Congress' optimal delegation decision depends on the likelihood of the efficient firm $\nu$ and the weight $\alpha_{c}$ Congress assigns to profits. A lower $\alpha_{c}$ relaxes the condition $\nu>\nu^{*}\left(\alpha_{c}\right)$ and thereby increases the scope where strategic delegation is optimal. This is because a regulator with a pure consumer standard better reflects the preferences of a Congress with a greater interest in consumer surplus. Consequently, our model predicts that strategic delegation should be prevalent in countries where firms are expected to be relatively efficient and policy makers are, a priori, already more concerned with consumers' well-being. These implications may lend themselves for an empirical validation of our results. 


\section{Conclusions}

In this paper we show that strategic delegation to an independent regulator with a pure consumer standard improves dynamic regulation by mitigating ratchet effects associated with short term contracting. These results are formally derived in a repeated version of the Baron and Myerson (1982) model, which allows a full characterization of the optimal regulatory contract. Despite its stylized formulation, the formal analysis suggests that the principles underlying our results are general. Ultimately, the dynamic incentive problem with short term contracting is that the regulator cannot refrain from rent expropriation once he has learned the firm's private information. A pure consumer standard, which places more emphasis on firm's rent extraction, alleviates the regulator's myopic temptation to raise the production of the inefficient firm after learning private information, and therefore limits the need for rents to the efficient firm. This mitigates ratchet effects but comes at the cost of a further output distortion for the inefficient firm, in comparison to the genuine social welfare function. Consequently, strategic delegation with a pure consumer standard is optimal if the efficient firm is sufficiently likely so that benefits outweigh costs. Otherwise, a regulator with an unbiased welfare perspective is preferable. 


\section{Appendix 1}

This appendix collects the proofs.

Proof of Lemma 1: Maximizing (3) for $q_{l}$ yields $q_{l}=1$, while $q_{h}=1$ maximizes (3) for $\nu<\bar{\nu}$ and $q_{h}=0$ maximizes (3) for $\nu \geq \bar{\nu} .^{13}$ The values for $t_{l}$ and $t_{h}$ obtain from the binding participation constraint of the inefficient firm, $t_{h}=c_{h} q_{h}$, and the binding incentive constraint of the efficient firm, $t_{l}=c_{l} q_{l}+\Delta c q_{h}$

Q.E.D.

Proof of Lemma 2: The proof follows from the argument in Laffont and Tirole (1993, p. 104) that if some different, possibly time variant contract is optimal, then one can construct an appropriate possibly random contract for the static problem that leads to a higher payoff. This would contradict the optimality of the optimal static contract of Lemma $1 .^{14}$

Q.E.D.

Proof of Lemma 3: Consider the first period contract menu $\gamma_{1 l}=\gamma_{1 h}=\left(1, c_{h}\right)$. It follows that for $\nu<\bar{\nu}$ an outcome $\Gamma$ with $\beta_{l}=\beta_{h}=1, \nu_{2 l}=\nu_{2 h}=\nu$, and $\gamma_{2 l l}=\gamma_{2 l h}=\gamma_{2 h l}=\gamma_{2 h h}=\left(1, c_{h}\right)$ constitutes a perfect Bayesian equilibrium, because it satisfies Bayes' consistency, sequential rationality, and optimal reporting. It yields the regulator $W_{l}^{f c}=(1+\rho)\left(S-c_{l}-\left(1-\alpha_{r}\right) \Delta c\right)$ when facing a cost type $c_{l}$ and $W_{h}^{f c}=(1+\rho)\left(S-c_{h}\right)$ when facing a cost type $c_{h}$. These payoffs coincide with those under the optimal long term contract of Lemma 2. Because the regulator cannot improve on long term contracting, the contract described in the lemma is also optimal.

Q.E.D.

Proof of Lemma 4: Given the reporting strategies $\left(\beta_{l}, \beta_{h}\right)$, Bayes' consistency implies $\nu_{2 l}=\nu_{l}\left(\beta_{l}, \beta_{h}\right)$ and $\nu_{2 h}=\nu_{h}\left(\beta_{l}, \beta_{h}\right)$. Because $\nu_{l}\left(\beta_{l}, \beta_{h}\right) \geq \nu$, the lemma's supposition $\nu \geq \bar{\nu}$ implies $\nu_{l}\left(\beta_{l}, \beta_{h}\right) \geq \bar{\nu}$. By Lemma 1, sequential rationality implies $\left\{\gamma_{2 l l}, \gamma_{2 l h}\right\}=\left\{\left(1, c_{l}\right),(0,0)\right\}$, while $\gamma_{2 h l}=\gamma_{2 h h}=\left(1, c_{h}\right)$ if $\nu_{h}\left(\beta_{l}, \beta_{h}\right)<\bar{\nu}$, and $\left\{\gamma_{2 h l}, \gamma_{2 h h}\right\}=\left\{\left(1, c_{l}\right),(0,0)\right\}$ if $\nu_{h}\left(\beta_{l}, \beta_{h}\right) \geq \bar{\nu}$

Proof of Lemma 5: Suppose to the contrary that a PBE outcome with $\nu_{h}\left(\beta_{l}, \beta_{h}\right)<\bar{\nu}$ exists. Lemma 4 implies that in any such PBE the efficient firm receives a rent $t_{2 h l}-c_{l} q_{2 h l}=\Delta c$ after reporting type $c_{h}$ in the first period. Hence, the necessary condition (7) reduces to $t_{1 l}-t_{1 h}-c_{l}\left(q_{1 l}-q_{1 h}\right) \geq \rho \Delta c$, whereas the necessary condition (8) implies $t_{1 h}-t_{1 l}+c_{h}\left(q_{1 l}-q_{1 h}\right) \geq 0$. Adding both inequalities and dividing by $\Delta c$ yields $q_{1 l}-q_{1 h} \geq \rho$, which contradicts $q_{1 l}, q_{1 h} \in[0,1]$ and $\rho>1$. Hence, we must have $\nu_{h}\left(\beta_{l}, \beta_{h}\right) \geq \bar{\nu}$ in any PBE outcome. Using (4), this is equivalent to $\beta_{l} \leq \bar{\beta}_{l}\left(\beta_{h}\right)$.

Q.E.D.

\footnotetext{
${ }^{13}$ Note that for $\nu=\bar{\nu}$ the solution is not unique and any $q_{h} \in[0,1]$ maximizes (3). We pick the solution $q_{h}=0$, because only this choice ensures the existence of an optimal contract in the dynamic regulatory game.

${ }^{14}$ That a non-degenerate random contract is suboptimal follows directly from Strausz (2006).
} 
Proof of Lemma 6: It follows from Lemma 5 that $\beta_{l} \in(0,1)$, which implies that the incentive constraint (5) is equivalent to the constraint (7) satisfied with equality. Moreover, at least one of the participation constraints (10) or $(11)$ in $P^{o}$ is binding at the optimum, because if they were both slack, one could raise the regulatory objective $V$ in $P^{o}$ by reducing $t_{1 l}$ and $t_{1 h}$ by the same degree, as this neither affects (5) nor (6). Moreover, this binding constraint must be (11), since, as usual, the necessary conditions (7) and (8) - which follow from (5) and (6) - and the participation constraint of the inefficient firm (11) imply the participation constraint of the efficient firm (10): $\beta_{l}\left(t_{1 l}-c_{l} q_{1 l}\right)+\left(1-\beta_{l}\right)\left(t_{1 h}-c_{l} q_{1 h}\right) \geq t_{1 h}-c_{l} q_{1 h}=\beta_{h}\left(t_{1 h}-c_{h} q_{1 h}\right)+\left(1-\beta_{h}\right)\left(t_{1 h}-c_{h} q_{1 h}\right)+\Delta c q_{1 h} \geq$ $\beta_{h}\left(t_{1 h}-c_{h} q_{1 h}\right)+\left(1-\beta_{h}\right)\left(t_{1 l}-c_{h} q_{1 l}\right)+\Delta c q_{1 h} \geq \Delta c q_{1 h} \geq 0$.

Consequently, a solution to $P^{o}$ coincides with a solution to a transformed problem, where constraint (5) is replaced by the binding constraint (7) together with $t_{2 h l}=c_{l}$ and $q_{2 h l}=1$ (by the combination of Lemma 4 and Lemma 5), the constraint (11) is satisfied with equality, and the constraint (10) is disregarded.

We solve this transformed problem in two steps. First, we check whether $\beta_{h} \in(0,1)$ is optimal. If this is the case, then (6) is equivalent to (8) satisfied with equality and the transformed problem becomes

$$
\begin{array}{ll}
P^{\prime}: \max _{\beta_{l}, \beta_{h}, q_{1 l}, q_{1 h}, t_{1 l}, t_{1 h}} & V \\
\text { s.t. } & t_{1 l}-c_{l} q_{1 l}=t_{1 h}-c_{l} q_{1 h} \\
& t_{1 h}-c_{h} q_{1 h}=t_{1 l}-c_{h} q_{1 l} \\
& \beta_{h}\left(t_{1 h}-c_{h} q_{1 h}\right)+\left(1-\beta_{h}\right)\left(t_{1 l}-c_{h} q_{1 l}\right)=0 \\
& \beta_{l} \leq \bar{\beta}_{l}\left(\beta_{h}\right),
\end{array}
$$

where $V$ is given by (9). Constraints (14) and (15) imply $t_{1 h}=c_{h} q_{1 h}$ and $t_{1 l}=c_{h} q_{1 l}$. Using in addition (13), it follows $q_{1 l}=q_{1 h}$. Substituting out these three variables, the objective function $V$ in $P^{\prime}$ simplifies to

$$
\nu\left[\left(S-c_{h}+\alpha_{r} \Delta c\right) q_{1 l}+\rho\left(S-c_{l}\right)\right]+(1-\nu)\left(S-c_{h}\right) q_{1 l},
$$

which must be maximized with respect to $q_{1 l}$ under (16). The expression is independent of $\beta_{l}$ and $\beta_{h}$ and maximized for $q_{1 l}=1$. This implies $q_{1 h}=1, t_{1 l}=t_{1 h}=c_{h}$ with $\beta_{l}+\beta_{h}=1,{ }^{15}$ and yields the regulator the payoff

$$
V^{p} \equiv S-c_{h}+\nu \alpha_{r} \Delta c+\nu \rho\left(S-c_{l}\right)
$$

We next check whether $\beta_{h}=1$ is optimal, while not being a solution to $P^{\prime}{ }^{16}$ If this is the case,

\footnotetext{
${ }^{15}$ Notice that (16) is satisfied at the optimum.

${ }^{16}$ If $\beta_{h}=1$ is optimal and at the same time a solution to $P^{\prime}$, then the regulator's optimal payoff is actually $V^{p}$.
} 
then at any solution (14) is satisfied with a strict inequality rather than an equality. Using $\beta_{h}=1$, (15) simplifies to $t_{1 h}=c_{h} q_{1 h}$, so that (13) implies $t_{1 l}=c_{l} q_{1 l}+\Delta c q_{1 h}$. Consequently, (14) with a strict inequality implies $q_{1 h}<q_{1 l}$ and, moreover, the objective $V$ simplifies to

$$
\nu \beta_{l}\left(S-c_{l}\right)\left(q_{1 l}+\rho\right)+\nu\left(1-\beta_{l}\right)\left(S-c_{l}\right)\left(q_{1 h}+\rho\right)-\nu\left(1-\alpha_{r}\right) \Delta c q_{1 h}+(1-\nu)\left(S-c_{h}\right) q_{1 h} .
$$

The expression is increasing in $q_{1 l}$ so that $q_{1 l}=1$ is optimal. This implies that (14) is only satisfied with a strict inequality if $q_{1 h}<q_{1 l}=1$. Since the expression is linear in $q_{1 h}$, then $\beta_{h}=1$ is optimal, while not being a solution to $P^{\prime}$, when the expression is decreasing in $q_{1 h}$ so that $q_{1 h}=0$ must be optimal. ${ }^{17}$ Therefore, the expression is increasing in $\beta_{l}$ so that (16) must bind at the optimum. If $\beta_{h}=1$ is optimal while not being a solution to $P^{\prime}$, then we get $\beta_{l}=\bar{\beta}_{l}(1) \equiv \widehat{\beta}_{l}\left(\alpha_{r}\right)$ and the regulator's payoff becomes

$$
V^{p s} \equiv \nu\left(S-c_{l}\right)\left(\widehat{\beta}_{l}\left(\alpha_{r}\right)+\rho\right)=\nu\left(S-c_{l}\right)\left[1+\rho-\frac{(1-\nu)\left(S-c_{h}\right)}{\left(1-\alpha_{r}\right) \nu \Delta c}\right] .
$$

Straightforward computations reveal that $V^{p s} \geq V^{p}$ if and only if $\nu \geq \tilde{\nu}$.

The second period contract menus $\left\{\gamma_{2 l l}, \gamma_{2 l h}\right\}=\left\{\gamma_{2 h l}, \gamma_{2 h h}\right\}=\left\{\left(1, c_{l}\right),(0,0)\right\}$ follow from the combination of Lemma 4 and Lemma 5.

Q.E.D.

Proof of Proposition 1: The proof follows directly from Lemma 3 and Lemma 6.

Q.E.D.

Proof of Proposition 2: With $\alpha_{r}=\alpha_{c}$ the regulator implements Congress' optimal long term contract in Lemma 2. Hence, for some $\alpha_{r} \neq \alpha_{c}$ Congress cannot obtain a strictly larger payoff, as this would violate the optimality of the long term contract in Lemma 2.

Q.E.D.

Proof of Proposition 3: The proof goes through the following four steps.

Step 1: Suppose $\nu<\bar{\nu}\left(\alpha_{c}\right)$. Then, $\alpha_{r}=\alpha_{c}$ is optimal, because $\alpha_{r}=\alpha_{c}$ induces the regulator to implement the contract in Lemma 3, which coincides with Congress' optimal long term contract.

Step 2: Suppose $\nu \geq \bar{\nu}\left(\alpha_{c}\right)$. We show that Congress prefers $\alpha_{r}=\alpha_{c}$ to any $\alpha_{r}>\alpha_{c}$. To see this, note first that $\bar{\nu}$ and $\widetilde{\nu}$ are strictly increasing in $\alpha_{r}$, so that $\alpha_{c}<\alpha_{r}$ implies $\bar{\nu}\left(\alpha_{c}\right)<\bar{\nu}\left(\alpha_{r}\right)$ and $\tilde{\nu}\left(\alpha_{c}\right)<\tilde{\nu}\left(\alpha_{r}\right)$. Moreover, $\bar{\nu}\left(\alpha_{r}\right)<\tilde{\nu}\left(\alpha_{r}\right)$ and $\bar{\nu}\left(\alpha_{c}\right)<\tilde{\nu}\left(\alpha_{c}\right)$. Hence, we have either the ordering $\bar{\nu}\left(\alpha_{c}\right)<\bar{\nu}\left(\alpha_{r}\right)<\tilde{\nu}\left(\alpha_{c}\right)<\tilde{\nu}\left(\alpha_{r}\right)$ or the ordering $\bar{\nu}\left(\alpha_{c}\right)<\tilde{\nu}\left(\alpha_{c}\right) \leq \bar{\nu}\left(\alpha_{r}\right)<\tilde{\nu}\left(\alpha_{r}\right)$. Depending on $\nu \in(0,1)$, we distinguish the following four cases under the first ordering:

(i) For $\nu \in\left[\bar{\nu}\left(\alpha_{c}\right), \bar{\nu}\left(\alpha_{r}\right)\right)$ it follows from (12) that $W\left(\alpha_{c}\right)-W\left(\alpha_{r}\right)=W^{p}-W^{f c}=S-c_{h}+\nu \alpha_{c} \Delta c+$ $\nu \rho\left(S-c_{l}\right)-(1+\rho)\left(S-c_{h}+\nu \alpha_{c} \Delta c\right) \geq 0$, where the inequality holds since $\nu \geq \bar{\nu}\left(\alpha_{c}\right)$.

\footnotetext{
${ }^{17}$ From the first-order condition for $q_{1 h}$ this is the case if and only if $\beta_{l} \geq \widetilde{\beta}_{l}$, where $\widetilde{\beta}_{l} \equiv 1-\frac{\nu\left(1-\alpha_{r}\right) \Delta c-(1-\nu)\left(S-c_{h}\right)}{\nu\left(S-c_{l}\right)}$. Notice that $\widetilde{\beta}_{l} \leq \bar{\beta}_{l}(1)$ for $\nu \geq \widetilde{\nu}$, so that the interval $\left[\widetilde{\beta}_{l}, \bar{\beta}_{l}(1)\right]$ is non-empty.
} 
(ii) For $\nu \in\left[\bar{\nu}\left(\alpha_{r}\right), \tilde{\nu}\left(\alpha_{c}\right)\right)$ it follows from (12) that $W\left(\alpha_{c}\right)-W\left(\alpha_{r}\right)=W^{p}-W^{p}=0$.

(iii) For $\nu \in\left[\tilde{\nu}\left(\alpha_{c}\right), \tilde{\nu}\left(\alpha_{r}\right)\right)$ it follows from (12) that $W\left(\alpha_{c}\right)-W\left(\alpha_{r}\right)=W^{p s}\left(\alpha_{c}\right)-W^{p}=\nu(S-$ $\left.c_{l}\right)\left(\hat{\beta}_{l}\left(\alpha_{c}\right)+\rho\right)-\left[S-c_{h}+\nu \alpha_{c} \Delta c+\nu \rho\left(S-c_{l}\right)\right] \geq 0$, where the inequality holds since $\nu \geq \tilde{\nu}\left(\alpha_{c}\right)$.

(iv) For $\nu \geq \tilde{\nu}\left(\alpha_{r}\right)$ it follows from (12) that $W\left(\alpha_{c}\right)-W\left(\alpha_{r}\right)=W^{p s}\left(\alpha_{c}\right)-W^{p s}\left(\alpha_{r}\right)=\nu(S-$ $\left.c_{l}\right)\left(\hat{\beta}_{l}\left(\alpha_{c}\right)+\rho\right)-\nu\left(S-c_{l}\right)\left(\hat{\beta}_{l}\left(\alpha_{r}\right)+\rho\right)>0$, where the inequality holds since $\hat{\beta}_{l}($.$) is strictly decreas-$ ing.

Under the second ordering we obtain the following four cases:

(v) For $\nu \in\left[\bar{\nu}\left(\alpha_{c}\right), \tilde{\nu}\left(\alpha_{c}\right)\right)$ it follows from case (i) that $W\left(\alpha_{c}\right)-W\left(\alpha_{r}\right)=W^{p}-W^{f c} \geq 0$.

(vi) For $\nu \in\left[\tilde{\nu}\left(\alpha_{c}\right), \bar{\nu}\left(\alpha_{r}\right)\right)$ it follows from (12) that $W\left(\alpha_{c}\right)-W\left(\alpha_{r}\right)=W^{p s}\left(\alpha_{c}\right)-W^{f c}=\nu(S-$ $\left.c_{l}\right)\left(\hat{\beta}_{l}\left(\alpha_{c}\right)+\rho\right)-(1+\rho)\left(S-c_{h}+\nu \alpha_{c} \Delta c\right)>0$, where the inequality holds since $\nu \geq \tilde{\nu}\left(\alpha_{c}\right)$.

(vii) For $\nu \in\left[\bar{\nu}\left(\alpha_{r}\right), \tilde{\nu}\left(\alpha_{r}\right)\right)$ it follows from case (iii) that $W\left(\alpha_{c}\right)-W\left(\alpha_{r}\right)=W^{p s}\left(\alpha_{c}\right)-W^{p} \geq 0$.

(viii) For $\nu \geq \tilde{\nu}\left(\alpha_{r}\right)$ it follows from case (iv) that $W\left(\alpha_{c}\right)-W\left(\alpha_{r}\right)=W^{p s}\left(\alpha_{c}\right)-W^{p s}\left(\alpha_{r}\right)>0$.

Step 3: If $\nu>\nu^{*}\left(\alpha_{c}\right)$, Congress strictly prefers $\alpha_{r}=0$ to $\alpha_{r}=\alpha_{c}$. Otherwise, Congress prefers $\alpha_{r}=\alpha_{c}$ to $\alpha_{r}=0$. To see this, note first that we have either the ordering $\bar{\nu}(0)<\bar{\nu}\left(\alpha_{c}\right)<\tilde{\nu}(0)<\tilde{\nu}\left(\alpha_{c}\right)$ or the ordering $\bar{\nu}(0)<\tilde{\nu}(0) \leq \bar{\nu}\left(\alpha_{c}\right)<\tilde{\nu}\left(\alpha_{c}\right)$. The first ordering reduces to $\bar{\nu}\left(\alpha_{c}\right)<\tilde{\nu}(0)<\tilde{\nu}\left(\alpha_{c}\right)$ and the second ordering reduces to $\bar{\nu}\left(\alpha_{c}\right)<\tilde{\nu}\left(\alpha_{c}\right)$, since Step 1 implies that Congress finds it optimal to set $\alpha_{r}=\alpha_{c}$ for $\nu<\bar{\nu}\left(\alpha_{c}\right)$. Depending on $\nu \in(0,1)$, we distinguish the following three cases under the first ordering:

(ix) For $\nu \in\left[\bar{\nu}\left(\alpha_{c}\right), \widetilde{\nu}(0)\right)$ it follows from (12) that $W(0)-W\left(\alpha_{c}\right)=W^{p}-W^{p}=0$.

$(\mathrm{x})$ For $\nu \in\left[\widetilde{\nu}(0), \widetilde{\nu}\left(\alpha_{c}\right)\right)$ it follows from (12) that $W(0)-W\left(\alpha_{c}\right)=W^{p s}(0)-W^{p}=\nu(S-$ $\left.c_{l}\right)\left(\hat{\beta}_{l}(0)+\rho\right)-\left[S-c_{h}+\nu \alpha_{c} \Delta c+\nu \rho\left(S-c_{l}\right)\right]>0$ if and only if $\nu>\nu^{*}\left(\alpha_{c}\right) \in\left(\widetilde{\nu}(0), \widetilde{\nu}\left(\alpha_{c}\right)\right)$.

(xi) For $\nu \geq \widetilde{\nu}\left(\alpha_{c}\right)$ it follows from (12) that $W(0)-W\left(\alpha_{c}\right)=W^{p s}(0)-W^{p s}\left(\alpha_{c}\right)=\nu(S-$ $\left.c_{l}\right)\left(\hat{\beta}_{l}(0)+\rho\right)-\nu\left(S-c_{l}\right)\left(\hat{\beta}_{l}\left(\alpha_{c}\right)+\rho\right)>0$, where the inequality holds since $\hat{\beta}_{l}($.$) is strictly decreasing.$ The second ordering yields the following two cases:

(xii) For $\nu \in\left[\bar{\nu}\left(\alpha_{c}\right), \widetilde{\nu}\left(\alpha_{c}\right)\right)$ it follows from case $(\mathrm{x})$ that $W(0)-W\left(\alpha_{c}\right)=W^{p s}(0)-W^{p}>0$ if and only if $\nu>\nu^{*}\left(\alpha_{c}\right) \in\left(\bar{\nu}\left(\alpha_{c}\right), \widetilde{\nu}\left(\alpha_{c}\right)\right)$.

(xiii) For $\nu \geq \widetilde{\nu}\left(\alpha_{c}\right)$ it follows from case (xi) that $W(0)-W\left(\alpha_{c}\right)=W^{p s}(0)-W^{p s}\left(\alpha_{c}\right)>0$.

Step 4: Congress prefers either $\alpha_{r}=0$ or $\alpha_{r}=\alpha_{c}$ to any $\alpha_{r} \in\left(0, \alpha_{c}\right)$. To see this, substitute $\alpha_{r}=0$ with $\alpha_{r} \in\left(0, \alpha_{c}\right)$ in Step 3. This does not affect welfare in case (ix) but reduces welfare in cases (x) and (xi) or in cases (xii) and (xiii), since $W^{p s}$ decreases in $\alpha_{r}$.

Proposition 3 follows from combining Steps 1, 2, 3, 4 .

Q.E.D. 


\section{Appendix 2}

This appendix extends our results to the case $\rho \leq 1$. Defining

$$
\bar{\rho} \equiv \frac{(1-\nu)\left(S-c_{l}\right)\left(S-c_{h}\right)}{\left(1-\alpha_{r}\right) \Delta c\left[\nu\left(1-\alpha_{r}\right) \Delta c-(1-\nu)\left(S-c_{h}\right)\right]},
$$

we can characterize the optimal regulatory policy in the following proposition.

Proposition 4 (optimal regulation with short term contracting) Suppose $0<\rho \leq 1$. The optimal two-period regulatory policy with short term contracting depends on the likelihood of the effcient firm, $\nu \in(0,1)$, as follows:

(i) For $\nu<\bar{\nu}$ it coincides with the solution under long term contracting and consists of a first period full pooling menu $\gamma_{1 l}=\gamma_{1 h}=\left(1, c_{h}\right)$ with reporting strategies $\beta_{l}+\beta_{h}=1$, and a PBE outcome $\Gamma$ with full pooling menus $\gamma_{2 l l}=\gamma_{2 l h}=\gamma_{2 h l}=\gamma_{2 h h}=\left(1, c_{h}\right)$.

(ii) For $\nu \in[\bar{\nu}, \tilde{\nu})$, and for $\nu \geq \tilde{\nu}$ together with $\rho<\bar{\rho} \in(0,1]$, it consists of a first period full separation menu $\left\{\gamma_{1 l}, \gamma_{1 h}\right\}=\left\{\left(1, c_{l}+\rho \Delta c\right),(0,0)\right\}$ with reporting strategies $\beta_{l}=\beta_{h}=1$, and a PBE outcome $\Gamma$ with full separation menus $\left\{\gamma_{2 l l}, \gamma_{2 l h}\right\}=\left\{\gamma_{2 h l}, \gamma_{2 h h}\right\}=\left\{\left(1, c_{l}\right),\left(1, c_{h}\right)\right\}$.

(iii) For $\nu \geq \tilde{\nu}$ and $\rho \geq \bar{\rho} \in(0,1]$ it consists of a first period partial separation menu $\left\{\gamma_{1 l}, \gamma_{1 h}\right\}=$ $\left\{\left(1, c_{l}\right),(0,0)\right\}$ with reporting strategies $\beta_{l}=\bar{\beta}_{l}(1)$ and $\beta_{h}=1$, and a PBE outcome $\Gamma$ with full separation menus $\left\{\gamma_{2 l l}, \gamma_{2 l h}\right\}=\left\{\gamma_{2 h l}, \gamma_{2 h h}\right\}=\left\{\left(1, c_{l}\right),(0,0)\right\}$.

Proof of Proposition 4: Following the same approach as in the proof of Lemma 6, it is straightforward to show that the participation constraint of the efficient firm is slack, while the participation constraint of the inefficient firm is binding in equilibrium. The regulator's problem becomes

$$
\begin{aligned}
P^{\prime \prime}: \max _{\beta_{l}, \beta_{h}, q_{1 l}, q_{1 h}, t_{1 l}, t_{1 h}} & \nu\left\{\beta_{l}\left[S q_{1 l}-t_{1 l}+\alpha_{r}\left(t_{1 l}-c_{l} q_{1 l}\right)+\rho W_{l}\left(\nu_{2 l}\right)\right]\right. \\
+ & \left.\left(1-\beta_{l}\right)\left[S q_{1 h}-t_{1 h}+\alpha_{r}\left(t_{1 h}-c_{l} q_{1 h}\right)+\rho W_{l}\left(\nu_{2 h}\right)\right]\right\} \\
+ & (1-\nu)\left\{\beta_{h}\left[S q_{1 h}-t_{1 h}+\alpha_{r}\left(t_{1 h}-c_{h} q_{1 h}\right)+\rho W_{h}\left(\nu_{2 h}\right)\right]\right. \\
& \left.+\left(1-\beta_{h}\right)\left[S q_{1 l}-t_{1 l}+\alpha_{r}\left(t_{1 l}-c_{h} q_{1 l}\right)+\rho W_{h}\left(\nu_{2 l}\right)\right]\right\} \\
\text { s.t. } \quad & t_{1 l}-c_{l} q_{1 l} \geq t_{1 h}-c_{l} q_{1 h}+\rho\left(t_{2 h l}-c_{l} q_{2 h l}\right) \\
& t_{1 h}-c_{h} q_{1 h} \geq t_{1 l}-c_{h} q_{1 l} \\
& \beta_{h}\left(t_{1 h}-c_{h} q_{1 h}\right)+\left(1-\beta_{h}\right)\left(t_{1 l}-c_{h} q_{1 l}\right)=0,
\end{aligned}
$$

where the incentive constraints (18) and (19) hold with equality if $\beta_{l} \in(0,1)$ and $\beta_{h} \in(0,1)$, respectively. We have to consider the following four cases: (I) $\beta_{l}=\beta_{h}=1 ;$ (II) $\beta_{l} \in(0,1), \beta_{h} \in(0,1)$; (III) 
$\beta_{l}=1, \beta_{h} \in(0,1) ;(\mathrm{IV}) \beta_{l} \in(0,1), \beta_{h}=1$. We know from Lemma 3 that for $\nu \leq \bar{\nu}$ the solution to the regulatory problem coincides with the solution under long term contracting, and thus we can restrict attention to $\nu \geq \bar{\nu}$.

Case I $\left(\beta_{l}=\beta_{h}=1\right)$. Standard arguments imply that (18) is binding, while (19) can be neglected. Substituting $t_{1 h}=c_{h} q_{1 h}$ from (20) and $t_{1 l}=c_{l} q_{1 l}+\Delta c q_{1 h}+\rho \Delta c$ from (18) into (17) the regulator's objective becomes

$$
\nu\left[S q_{1 l}-c_{l} q_{1 l}-\left(1-\alpha_{r}\right) \Delta c q_{1 h}+\rho\left(S-c_{l}-\left(1-\alpha_{r}\right) \Delta c\right)\right]+(1-\nu)\left[S q_{1 h}-c_{h} q_{1 h}+\rho\left(S-c_{l}\right)\right],
$$

which is maximized for $q_{1 l}=1$ and $q_{1 h}=0$. The regulator's payoff is

$$
V^{f s} \equiv \nu(1+\rho)\left(S-c_{l}\right)+\rho(1-\nu)\left(S-c_{h}\right)-\nu \rho\left(1-\alpha_{r}\right) \Delta c
$$

Case II $\left(\beta_{l} \in(0,1), \beta_{h} \in(0,1)\right)$. Note that both (18) and (19) are binding, which implies after some manipulation $q_{1 l}-q_{1 h}=\frac{\rho}{\Delta c}\left(t_{2 h l}-c_{l} q_{2 h l}\right)$. Moreover, from (20) we obtain $t_{1 h}=c_{h} q_{1 h}$ and $t_{1 l}=c_{h} q_{1 l}$. Two possible subcases arise.

(i) $\nu_{2 h}<\bar{\nu}$. As $t_{2 h l}-c_{l} q_{2 h l}=\Delta c$ by Lemma 4, we have $q_{1 l}=q_{1 h}+\rho$, with $q_{1 h} \in[0,1-\rho]$ since $q_{1 l}, q_{1 h} \in[0,1]$. Substituting these conditions into (17) the regulator's payoff becomes

$$
\begin{aligned}
& \nu\left\{\beta_{l}\left[\left(S-c_{h}\right)\left(q_{1 h}+\rho\right)+\alpha_{r}\left(q_{1 h}+\rho\right) \Delta c+\rho\left(S-c_{l}\right)\right]\right. \\
& \left.+\left(1-\beta_{l}\right)\left[S q_{1 h}-c_{h} q_{1 h}+\alpha_{r} \Delta c q_{1 h}+\rho\left(S-c_{l}-\left(1-\alpha_{r}\right) \Delta c\right)\right]\right\} \\
& +(1-\nu)\left\{\beta_{h}\left[S q_{1 h}-c_{h} q_{1 h}+\rho\left(S-c_{h}\right)\right]+\left(1-\beta_{h}\right)\left(S-c_{h}\right)\left(q_{1 h}+\rho\right)\right\},
\end{aligned}
$$

which is maximized for $q_{1 h}=1-\rho$ and $q_{1 l}=1$. Hence, the regulator's payoff is $\nu\left(S-c_{h}+\alpha_{r} \Delta c\right)+$ $\nu \beta_{l} \rho\left(S-c_{l}\right)+(1-\nu)\left(S-c_{h}\right)<V^{f s}$ so that subcase $(i)$ is irrelevant.

(ii) $\nu_{2 h} \geq \bar{\nu}$. As $t_{2 h l}-c_{l} q_{2 h l}=0$ by Lemma 4 , we have $q_{1 l}=q_{1 h}$, and the regulator's payoff becomes $S q_{1 l}-c_{h} q_{1 l}+\nu \alpha_{r} \Delta c q_{1 l}+\nu \rho\left(S-c_{l}\right)$, which is maximized for $q_{1 l}=q_{1 h}=1$. The regulator's payoff is $S-c_{h}+\nu \alpha_{r} \Delta c+\nu \rho\left(S-c_{l}\right) \leq V^{f s}$, which implies that subcase (ii) is also irrelevant. Therefore, case II is irrelevant.

Case III $\left(\beta_{l}=1, \beta_{h} \in(0,1)\right)$. From the binding (19) and (20) we have $t_{1 h}=c_{h} q_{1 h}$ and $t_{1 l}=c_{h} q_{1 l}$. Substituting these conditions into (17) yields after some manipulation

$$
\nu\left[S q_{1 l}-c_{h} q_{1 l}+\alpha_{r} \Delta c q_{1 l}+\rho\left(S-c_{l}\right)\right]+(1-\nu)\left\{\beta_{h}\left[S q_{1 h}-c_{h} q_{1 h}+\rho\left(S-c_{h}\right)+\left(1-\beta_{h}\right)\left(S q_{1 l}-c_{h} q_{1 l}\right)\right]\right\}
$$


which is maximized for $q_{1 l}=1$. Since (18) implies $q_{1 l}>q_{1 h}$ and the regulator's objective is linear in $q_{1 h}$, we must have $q_{1 h}=0$ in equilibrium. The regulator's payoff is $S-c_{h}+\nu \alpha_{r} \Delta c+\nu \rho\left(S-c_{l}\right)-$ $(1-\nu) \beta_{h}(1-\rho)\left(S-c_{h}\right)<V^{p s}$, so that case III is irrelevant.

Case IV $\left(\beta_{l} \in(0,1), \beta_{h}=1\right)$. Note that the binding (18) and (20) imply $t_{1 h}=c_{h} q_{1 h}$ and $t_{1 l}=c_{l} q_{1 l}+\Delta c q_{1 h}+\rho\left(t_{2 h l}-c_{l} q_{2 h l}\right)$. Two subcases arise.

(i) $\nu_{2 h}<\bar{\nu}$. As $t_{2 h l}-c_{l} q_{2 h l}=\Delta c$ by Lemma 4 , (17) becomes

$$
\begin{aligned}
& \nu\left\{\beta_{l}\left[S q_{1 l}-c_{l} q_{1 l}-\Delta c q_{1 h}-\rho \Delta c+\alpha_{r} \Delta c\left(q_{1 h}+\rho\right)+\rho\left(S-c_{l}\right)\right]\right. \\
& \left.+\left(1-\beta_{l}\right)\left[S q_{1 h}-c_{h} q_{1 h}+\alpha_{r} \Delta c q_{1 h}+\rho\left(S-c_{l}-\left(1-\alpha_{r}\right) \Delta c\right)\right]\right\} \\
& +(1-\nu)\left[S q_{1 h}-c_{h} q_{1 h}+\rho\left(S-c_{h}\right)\right]
\end{aligned}
$$

which is maximized for $q_{1 l}=1$. Summing (18) and (19) implies $q_{1 l}>q_{1 h}$. Since the regulator's objective is linear in $q_{1 h}$, we must have $q_{1 h}=0$ in equilibrium. The regulator's payoff becomes $\nu \rho\left(S-c_{h}+\alpha_{r} \Delta c\right)+\nu \beta_{l}\left(S-c_{l}\right)+\rho(1-\nu)\left(S-c_{h}\right)<V^{f s}$ so that subcase $(i)$ is irrelevant.

(ii) $\nu_{2 h} \geq \bar{\nu}$. As $t_{2 h l}-c_{l} q_{2 h l}=0$ by Lemma 4 , (17) becomes

$$
\begin{aligned}
& \nu\left\{\beta_{l}\left[S q_{1 l}-c_{l} q_{1 l}-\Delta c q_{1 h}+\alpha_{r} \Delta c q_{1 h}+\rho\left(S-c_{l}\right)\right]\right. \\
& \left.+\left(1-\beta_{l}\right)\left[S q_{1 h}-c_{h} q_{1 h}+\alpha_{r} \Delta c q_{1 h}+\rho\left(S-c_{l}\right)\right]\right\}+(1-\nu)\left(S q_{1 h}-c_{h} q_{1 h}\right)
\end{aligned}
$$

s.t. $\quad \beta_{l} \leq \bar{\beta}_{l}(1) \equiv \widehat{\beta}_{l}\left(\alpha_{r}\right)$,

which is maximized for $q_{1 l}=1$. Summing (18) and (19) implies $q_{1 l} \geq q_{1 h}$. For $q_{1 l}=q_{1 h}$ (19) also holds with equality, and the solution is derived in case II. If (19) is slack at the optimum, i.e., $q_{1 l}>q_{1 h}$, then the linearity of the regulator's objective in $q_{1 h}$ implies $q_{1 h}=0 .{ }^{18}$ The regulator's payoff becomes after some manipulation $\nu\left(\beta_{l}+\rho\right)\left(S-c_{l}\right)$, which increases with $\beta_{l}$, so that $\beta_{l}=\widehat{\beta}_{l}\left(\alpha_{r}\right)$ is optimal. The payoff of the regulator becomes

$$
V^{p s} \equiv \nu\left(S-c_{l}\right)\left(\widehat{\beta}_{l}\left(\alpha_{r}\right)+\rho\right)=\nu\left(S-c_{l}\right)\left[1+\rho-\frac{(1-\nu)\left(S-c_{h}\right)}{\left(1-\alpha_{r}\right) \nu \Delta c}\right] .
$$

Standard computations yield $V^{p s} \geq V^{f s}$ if and only if $\nu \geq \widetilde{\nu}$ and $\rho \geq \bar{\rho} \in(0,1]$.

The second period contract menus $\left\{\gamma_{2 l l}, \gamma_{2 l h}\right\}$ and $\left\{\gamma_{2 h l}, \gamma_{2 h h}\right\}$ follow from Lemma 4.

Q.E.D.

Defining

$$
\rho^{*}\left(\alpha_{c}\right) \equiv \frac{(1-\nu)\left(S-c_{h}\right)\left(S-c_{l}\right)}{\Delta c\left[\nu\left(1-\alpha_{c}\right) \Delta c-(1-\nu)\left(S-c_{h}\right)\right]}
$$

\footnotetext{
${ }^{18}$ From the first-order condition for $q_{1 h}$ we find that $q_{1 h}=0$ is optimal if and only if $\beta_{l} \geq \widetilde{\beta}_{l}^{\prime} \equiv \frac{S-c_{h}+\nu \alpha_{r} \Delta c}{\nu\left(S-c_{l}\right)}$. Note that $\widetilde{\beta}_{l}^{\prime} \leq \widehat{\beta}_{l}\left(\alpha_{r}\right)$ for $\nu \geq \widetilde{\nu}$, so that the interval $\left[\widetilde{\beta}_{l}^{\prime}, \widehat{\beta}_{l}\left(\alpha_{r}\right)\right]$ is non-empty.
} 
the following proposition formalizes our result on strategic delegation for $0<\rho \leq 1$.

Proposition 5 (optimal delegation) Suppose $0<\rho \leq 1$. For $\nu>\nu^{*}\left(\alpha_{c}\right)$ and $\rho>\rho^{*}\left(\alpha_{c}\right) \in(0,1]$, Congress strictly benefits from strategic delegation. Optimal delegation assigns the regulator a profit weight $\alpha_{r}=0$, i.e., a pure consumer standard. Otherwise, Congress does not benefit from strategic delegation and finds it optimal to set a weight $\alpha_{r}=\alpha_{c}$, implying a regulator with an unbiased welfare perspective.

Proof of Proposition 5: The proof goes through the following four steps.

Step 1: Suppose $\nu<\bar{\nu}\left(\alpha_{c}\right)$. Then, $\alpha_{r}=\alpha_{c}$ is optimal, because $\alpha_{r}=\alpha_{c}$ induces the regulator to implement the contract in Lemma 3, which coincides with Congress' optimal long term contract.

Step 2: Suppose $\nu \geq \bar{\nu}\left(\alpha_{c}\right)$. We show that Congress prefers $\alpha_{r}=\alpha_{c}$ to any $\alpha_{r}>\alpha_{c}$. To see this, note first that $\bar{\rho}($.$) is strictly increasing in \alpha_{r}$. Moreover, $\bar{\nu}$ and $\widetilde{\nu}$ are also strictly increasing in $\alpha_{r}$. Hence, we have either the ordering $\bar{\nu}\left(\alpha_{c}\right)<\bar{\nu}\left(\alpha_{r}\right)<\widetilde{\nu}\left(\alpha_{c}\right)<\widetilde{\nu}\left(\alpha_{r}\right)$ or the ordering $\bar{\nu}\left(\alpha_{c}\right)<$ $\widetilde{\nu}\left(\alpha_{c}\right) \leq \bar{\nu}\left(\alpha_{r}\right)<\widetilde{\nu}\left(\alpha_{r}\right)$. Depending on $\nu \in(0,1)$, we distinguish the following four cases under the first ordering:

(i) For $\nu \in\left[\bar{\nu}\left(\alpha_{c}\right), \bar{\nu}\left(\alpha_{r}\right)\right)$ it follows from Proposition 4 that $W\left(\alpha_{c}\right)-W\left(\alpha_{r}\right)=W^{f s}-W^{f c}=$ $\nu(1+\rho)\left(S-c_{l}\right)+\rho(1-\nu)\left(S-c_{h}\right)-\nu \rho\left(1-\alpha_{r}\right) \Delta c-(1+\rho)\left(S-c_{h}+\nu \alpha_{c} \Delta c\right) \geq 0$, where the inequality holds since $\nu \geq \bar{\nu}\left(\alpha_{c}\right)$.

(ii) For $\nu \in\left[\bar{\nu}\left(\alpha_{r}\right), \widetilde{\nu}\left(\alpha_{c}\right)\right)$ it follows from Proposition 4 that $W\left(\alpha_{c}\right)-W\left(\alpha_{r}\right)=W^{f s}-W^{f s}=0$.

(iii) For $\nu \in\left[\widetilde{\nu}\left(\alpha_{c}\right), \widetilde{\nu}\left(\alpha_{r}\right)\right)$ it follows from Proposition 4 that (a) if $\rho<\bar{\rho}\left(\alpha_{c}\right)$, then $W\left(\alpha_{c}\right)-$ $W\left(\alpha_{r}\right)=W^{f s}-W^{f s}=0$; (b) if $\rho \geq \bar{\rho}\left(\alpha_{c}\right)$, then $W\left(\alpha_{c}\right)-W\left(\alpha_{r}\right)=W^{p s}\left(\alpha_{c}\right)-W^{f s}=\nu(S-$ $\left.c_{l}\right)\left(\hat{\beta}_{l}\left(\alpha_{c}\right)+\rho\right)-\left[\nu(1+\rho)\left(S-c_{l}\right)+\rho(1-\nu)\left(S-c_{h}\right)-\nu \rho\left(1-\alpha_{r}\right) \Delta c\right] \geq 0$, where the inequality holds since $\rho \geq \bar{\rho}\left(\alpha_{c}\right)$.

(iv) For $\nu \geq \widetilde{\nu}\left(\alpha_{r}\right)$ it follows from Proposition 4 that (a) if $\rho<\bar{\rho}\left(\alpha_{c}\right)$, then $W\left(\alpha_{c}\right)-W\left(\alpha_{r}\right)=$ $W^{f s}-W^{f s}=0$; (b) if $\rho \in\left[\bar{\rho}\left(\alpha_{c}\right), \bar{\rho}\left(\alpha_{r}\right)\right)$, then $W\left(\alpha_{c}\right)-W\left(\alpha_{r}\right)=W^{p s}\left(\alpha_{c}\right)-W^{f s} \geq 0$, where the inequality stems from case (iii(b)); (c) if $\rho \geq \bar{\rho}\left(\alpha_{r}\right)$, then $W\left(\alpha_{c}\right)-W\left(\alpha_{r}\right)=W^{p s}\left(\alpha_{c}\right)-W^{p s}\left(\alpha_{r}\right)=$ $\nu\left(S-c_{l}\right)\left(\hat{\beta}_{l}\left(\alpha_{c}\right)+\rho\right)-\nu\left(S-c_{l}\right)\left(\hat{\beta}_{l}\left(\alpha_{r}\right)+\rho\right)>0$, where the inequality holds since $\hat{\beta}_{l}($.$) is strictly$ decreasing.

The second ordering yields the following four cases:

(v) For $\nu \in\left[\bar{\nu}\left(\alpha_{c}\right), \widetilde{\nu}\left(\alpha_{c}\right)\right)$ it follows from case (i) that $W\left(\alpha_{c}\right)-W\left(\alpha_{r}\right)=W^{f s}-W^{f c} \geq 0$.

(vi) For $\nu \in\left[\widetilde{\nu}\left(\alpha_{c}\right), \bar{\nu}\left(\alpha_{r}\right)\right)$ it follows from Proposition 4 that (a) if $\rho<\bar{\rho}\left(\alpha_{c}\right)$, then $W\left(\alpha_{c}\right)-$ $W\left(\alpha_{r}\right)=W^{f s}-W^{f c} \geq 0$, where the inequality stems from case (i); (b) if $\rho \geq \bar{\rho}\left(\alpha_{c}\right)$, then $W\left(\alpha_{c}\right)-$ 
$W\left(\alpha_{r}\right)=W^{p s}\left(\alpha_{c}\right)-W^{f c}=\nu\left(S-c_{l}\right)\left(\hat{\beta}_{l}\left(\alpha_{c}\right)+\rho\right)-(1+\rho)\left(S-c_{h}+\nu \alpha_{c} \Delta c\right)>0$, where the inequality holds since $\nu \geq \tilde{\nu}\left(\alpha_{c}\right)$.

(vii) For $\nu \in\left[\bar{\nu}\left(\alpha_{r}\right), \widetilde{\nu}\left(\alpha_{r}\right)\right)$ it follows from Proposition 4 that (a) if $\rho<\bar{\rho}\left(\alpha_{c}\right)$, then $W\left(\alpha_{c}\right)-$ $W\left(\alpha_{r}\right)=W^{f s}-W^{f s}=0$; (b) if $\rho \geq \bar{\rho}\left(\alpha_{c}\right)$, then $W\left(\alpha_{c}\right)-W\left(\alpha_{r}\right)=W^{p s}\left(\alpha_{c}\right)-W^{f s} \geq 0$, where the inequality stems from case (iii(b)).

(viii) For $\nu \geq \widetilde{\nu}\left(\alpha_{r}\right)$ it follows from case (iv) that $W\left(\alpha_{c}\right)-W\left(\alpha_{r}\right) \geq 0$.

Step 3: If $\nu>\nu^{*}\left(\alpha_{c}\right)$ and $\rho>\rho^{*}\left(\alpha_{c}\right)$, Congress strictly prefers $\alpha_{r}=0$ to $\alpha_{r}=\alpha_{c}$. Otherwise, Congress prefers $\alpha_{r}=\alpha_{c}$ to $\alpha_{r}=0$. To see this, note first that we have either the ordering $\bar{\nu}(0)<$ $\bar{\nu}\left(\alpha_{c}\right)<\widetilde{\nu}(0)<\widetilde{\nu}\left(\alpha_{c}\right)$ or the ordering $\bar{\nu}(0)<\widetilde{\nu}(0) \leq \bar{\nu}\left(\alpha_{c}\right)<\widetilde{\nu}\left(\alpha_{c}\right)$. The first ordering reduces to $\bar{\nu}\left(\alpha_{c}\right)<\widetilde{\nu}(0)<\widetilde{\nu}\left(\alpha_{c}\right)$ and the second ordering reduces to $\bar{\nu}\left(\alpha_{c}\right)<\widetilde{\nu}\left(\alpha_{c}\right)$ since Step 1 implies that Congress finds it optimal to set $\alpha_{r}=\alpha_{c}$ for $\nu<\bar{\nu}\left(\alpha_{c}\right)$. Depending on $\nu \in(0,1)$, we distinguish the following three cases under the first ordering:

(ix) For $\nu \in\left[\bar{\nu}\left(\alpha_{c}\right), \widetilde{\nu}(0)\right)$ it follows from Proposition 4 that $W(0)-W\left(\alpha_{c}\right)=W^{f s}-W^{f s}=0$.

(x) For $\nu \in\left[\widetilde{\nu}(0), \widetilde{\nu}\left(\alpha_{c}\right)\right)$ it follows from Proposition 4 that (a) if $\rho<\bar{\rho}(0)$, then $W(0)-W\left(\alpha_{c}\right)=$ $W^{f s}-W^{f s}=0 ;(\mathrm{b})$ if $\rho \geq \bar{\rho}(0)$, then $W(0)-W\left(\alpha_{c}\right)=W^{p s}(0)-W^{f s}=\nu\left(S-c_{l}\right)\left(\hat{\beta}_{l}(0)+\rho\right)-$ $\left[\nu(1+\rho)\left(S-c_{l}\right)+\rho(1-\nu)\left(S-c_{h}\right)-\nu \rho\left(1-\alpha_{r}\right) \Delta c\right]>0$ if and only if $\rho>\rho^{*}\left(\alpha_{c}\right)$ with $\rho^{*}\left(\alpha_{c}\right) \in$ $[\bar{\rho}(0), 1]$ for $\nu \geq \nu^{*}\left(\alpha_{c}\right) \in\left(\widetilde{\nu}(0), \widetilde{\nu}\left(\alpha_{c}\right)\right)$.

(xi) For $\nu \geq \widetilde{\nu}\left(\alpha_{c}\right)$ it follows from Proposition 4 that (a) if $\rho<\bar{\rho}(0)$, then $W(0)-W\left(\alpha_{c}\right)=$ $W^{f s}-W^{f s}=0$; (b) if $\rho \in\left[\bar{\rho}(0), \bar{\rho}\left(\alpha_{c}\right)\right)$, then $W(0)-W\left(\alpha_{c}\right)=W^{p s}(0)-W^{f s}>0$ if and only if $\rho>\rho^{*}\left(\alpha_{c}\right)$ with $\rho^{*}\left(\alpha_{c}\right) \in\left[\bar{\rho}(0), \bar{\rho}\left(\alpha_{c}\right)\right)$, where the inequality stems from case (x(b)); (c) if $\rho \geq \bar{\rho}\left(\alpha_{c}\right)$, then $W(0)-W\left(\alpha_{c}\right)=W^{p s}(0)-W^{p s}\left(\alpha_{c}\right)=\nu\left(S-c_{l}\right)\left(\hat{\beta}_{l}(0)+\rho\right)-\nu\left(S-c_{l}\right)\left(\hat{\beta}_{l}\left(\alpha_{c}\right)+\rho\right)>0$, where the inequality holds since $\hat{\beta}_{l}($.$) is strictly decreasing.$

The second ordering yields the following two cases:

(xii) For $\nu \in\left[\bar{\nu}\left(\alpha_{c}\right), \widetilde{\nu}\left(\alpha_{c}\right)\right)$ it follows from case $(\mathrm{x})$ that $W(0)-W\left(\alpha_{c}\right)>0$ if and only if $\rho>\rho^{*}\left(\alpha_{c}\right)$ with $\rho^{*}\left(\alpha_{c}\right) \in[\bar{\rho}(0), 1]$ for $\nu \geq \nu^{*}\left(\alpha_{c}\right) \in\left(\bar{\nu}\left(\alpha_{c}\right), \widetilde{\nu}\left(\alpha_{c}\right)\right)$.

(xiii) For $\nu \geq \widetilde{\nu}\left(\alpha_{c}\right)$ it follows from case (xi) that $W(0)-W\left(\alpha_{c}\right)>0$ if and only if $\rho>\rho^{*}\left(\alpha_{c}\right)$.

Step 4: Congress prefers either $\alpha_{r}=0$ or $\alpha_{r}=\alpha_{c}$ to any $\alpha_{r} \in\left(0, \alpha_{c}\right)$. To see this, substitute $\alpha_{r}=0$ with $\alpha_{r} \in\left(0, \alpha_{c}\right)$ in the Step 3. This reduces welfare in cases $(\mathrm{x}(\mathrm{b})),(\mathrm{xi}(\mathrm{b}))$ and $(\mathrm{xi}(\mathrm{c}))$, or (xii) and (xiii), since $W^{p s}$ decreases in $\alpha_{r}$, while it does not affect welfare in all other cases.

The result in Proposition 5 follows from combining Steps 1, 2, 3, 4 .

Q.E.D. 


\section{References}

Armstrong, M., and Sappington, D. E. M. (2007). Recent developments in the theory of regulation. In: Armstrong, M., and Porter, R. (Eds.), Handbook of Industrial Organization, Elsevier B. V., 1557-1700.

Baron, D. P. (1988). Regulation and legislative choice. Rand Journal of Economics, 19(3), 467-477.

Baron, D. P., and Besanko, D. (1984). Regulation and information in a continuing relationship. Information Economics and Policy, 1(4) 267-302.

Baron, D. P., and Besanko, D. (1987). Commitment and fairness in a continuing relationship. Review of Economic Studies, 54(3), 413-436.

Baron, D. P., and Myerson, R. B. (1982). Regulating a monopolist with unknown costs. Econometrica, 50(4), 911-930.

Besanko, D., and Spulber, D. F. (1993). Contested mergers and equilibrium antitrust policy. Journal of Law, Economics \& Organization, 9(1), 1-29.

Bester, H., and Strausz, R. (2001). Contracting with imperfect commitment and the revelation principle: The single agent case. Econometrica, 69(4), 1077-1098.

Drugov, M. (2010). Information and delay in an agency model. Rand Journal of Economics, 41(3), 598-615.

Fershtman, C. (1985). Managerial incentives as a strategic variable in duopolistic environment. International Journal of Industrial Organization, 3(2) 245-253.

Fershtman, C., and Judd, K. L. (1987). Equilibrium incentives in oligopoly. American Economic Review, 77(5), 927-940.

Jansen, T., van Lier, A., and van Witteloostuijn, A. (2007). A note on strategic delegation: The market share case. International Journal of Industrial Organization, 25(3), 531-539.

Laffont, J.-J., and Tirole, J. (1986). Using cost observation to regulate firms. Journal of Political Economy, 94(3), 614-641.

Laffont, J.-J., and Tirole, J. (1987). Comparative statics of the optimal dynamic incentive contract. European Economic Review, 31(4), 901-926. 
Laffont, J.-J., and Tirole, J. (1988). The dynamics of incentive contracts. Econometrica, 56(5), 1153-1175.

Laffont, J.-J., and Tirole, J. (1990). Adverse selection and renegotiation in procurement. Review of Economic Studies, 57(4), 597-625.

Laffont, J.-J., and Tirole, J. (1993). A Theory of Incentives in Procurement and Regulation, MIT Press, Cambridge, MA.

Myerson, R. B. (1979). Incentive compatibility and the bargaining problem. Econometrica, 47(1), 61-73.

Newbery, D. M. (1999). Privatization, Restructuring and Regulation of Network Utilities, MIT Press, Cambridge, MA.

Rogoff, K. (1985). The optimal degree of commitment to an intermediate monetary target. Quarterly Journal of Economics, 100(4), 1169-1189.

Sklivas, S. D. (1987). The strategic choice of managerial incentives. Rand Journal of Economics, 18(3), 452-458.

Spulber, D. F., and Besanko, D. (1992). Delegation, commitment, and the regulatory mandate. Journal of Law, Economics $\&$ Organization, 8(1), 126-154.

Strausz, R. (2006). Deterministic versus stochastic mechanisms in principal-agent models. Journal of Economic Theory, 128(1), 306-314.

Vickers, J. (1985). Delegation and the theory of the firm. Economic Journal, 95, 138-147. 


\section{SFB 649 Discussion Paper Series 2012}

For a complete list of Discussion Papers published by the SFB 649, please visit http://sfb649.wiwi.hu-berlin.de.

001 "HMM in dynamic HAC models" by Wolfgang Karl Härdle, Ostap Okhrin and Weining Wang, January 2012.

002 "Dynamic Activity Analysis Model Based Win-Win Development Forecasting Under the Environmental Regulation in China" by Shiyi Chen and Wolfgang Karl Härdle, January 2012.

003 "A Donsker Theorem for Lévy Measures" by Richard Nickl and Markus Reiß, January 2012.

004 "Computational Statistics (Journal)" by Wolfgang Karl Härdle, Yuichi Mori and Jürgen Symanzik, January 2012.

005 "Implementing quotas in university admissions: An experimental analysis" by Sebastian Braun, Nadja Dwenger, Dorothea Kübler and Alexander Westkamp, January 2012.

006 "Quantile Regression in Risk Calibration" by Shih-Kang Chao, Wolfgang Karl Härdle and Weining Wang, January 2012.

007 "Total Work and Gender: Facts and Possible Explanations" by Michael Burda, Daniel S. Hamermesh and Philippe Weil, February 2012.

008 "Does Basel II Pillar 3 Risk Exposure Data help to Identify Risky Banks?" by Ralf Sabiwalsky, February 2012.

009 "Comparability Effects of Mandatory IFRS Adoption" by Stefano Cascino and Joachim Gassen, February 2012.

010 "Fair Value Reclassifications of Financial Assets during the Financial Crisis" by Jannis Bischof, Ulf Brüggemann and Holger Daske, February 2012.

011 "Intended and unintended consequences of mandatory IFRS adoption: A review of extant evidence and suggestions for future research" by Ulf Brüggemann, Jörg-Markus Hitz and Thorsten Sellhorn, February 2012.

012 "Confidence sets in nonparametric calibration of exponential Lévy models" by Jakob Söhl, February 2012.

013 "The Polarization of Employment in German Local Labor Markets" by Charlotte Senftleben and Hanna Wielandt, February 2012.

014 "On the Dark Side of the Market: Identifying and Analyzing Hidden Order Placements" by Nikolaus Hautsch and Ruihong Huang, February 2012.

015 "Existence and Uniqueness of Perturbation Solutions to DSGE Models" by Hong Lan and Alexander Meyer-Gohde, February 2012.

016 "Nonparametric adaptive estimation of linear functionals for low frequency observed Lévy processes" by Johanna Kappus, February 2012.

017 "Option calibration of exponential Lévy models: Implementation and empirical results" by Jakob Söhl und Mathias Trabs, February 2012.

018 "Managerial Overconfidence and Corporate Risk Management" by Tim R. Adam, Chitru S. Fernando and Evgenia Golubeva, February 2012.

019 "Why Do Firms Engage in Selective Hedging?" by Tim R. Adam, Chitru S. Fernando and Jesus M. Salas, February 2012.

020 "A Slab in the Face: Building Quality and Neighborhood Effects" by Rainer Schulz and Martin Wersing, February 2012.

021 "A Strategy Perspective on the Performance Relevance of the CFO" by Andreas Venus and Andreas Engelen, February 2012.

022 "Assessing the Anchoring of Inflation Expectations" by Till Strohsal and Lars Winkelmann, February 2012.

\section{SFB 649, Spandauer Straße 1, D-10178 Berlin http:/ / sfb649.wiwi.hu-berlin.de}

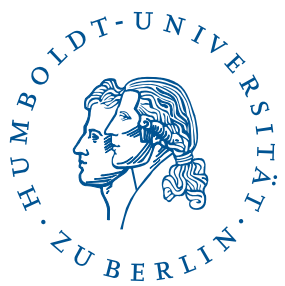




\title{
SFB 649 Discussion Paper Series 2012
}

For a complete list of Discussion Papers published by the SFB 649, please visit http://sfb649.wiwi.hu-berlin.de.

023 "Hidden Liquidity: Determinants and Impact" by Gökhan Cebiroglu and Ulrich Horst, March 2012.

024 "Bye Bye, G.I. - The Impact of the U.S. Military Drawdown on Local German Labor Markets" by Jan Peter aus dem Moore and Alexandra Spitz-Oener, March 2012.

025 "Is socially responsible investing just screening? Evidence from mutual funds" by Markus Hirschberger, Ralph E. Steuer, Sebastian Utz and Maximilian Wimmer, March 2012.

026 "Explaining regional unemployment differences in Germany: a spatial panel data analysis" by Franziska Lottmann, March 2012.

027 "Forecast based Pricing of Weather Derivatives" by Wolfgang Karl Härdle, Brenda López-Cabrera and Matthias Ritter, March 2012.

028 "Does umbrella branding really work? Investigating cross-category brand loyalty" by Nadja Silberhorn and Lutz Hildebrandt, April 2012.

029 "Statistical Modelling of Temperature Risk" by Zografia Anastasiadou, and Brenda López-Cabrera, April 2012.

030 "Support Vector Machines with Evolutionary Feature Selection for Default Prediction" by Wolfgang Karl Härdle, Dedy Dwi Prastyo and Christian Hafner, April 2012.

031 "Local Adaptive Multiplicative Error Models for High-Frequency Forecasts" by Wolfgang Karl Härdle, Nikolaus Hautsch and Andrija Mihoci, April 2012.

032 "Copula Dynamics in CDOs." by Barbara Choroś-Tomczyk, Wolfgang Karl Härdle and Ludger Overbeck, May 2012.

033 "Simultaneous Statistical Inference in Dynamic Factor Models" by Thorsten Dickhaus, May 2012.

034 "Realized Copula" by Matthias R. Fengler and Ostap Okhrin, Mai 2012.

035 "Correlated Trades and Herd Behavior in the Stock Market" by Simon Jurkatis, Stephanie Kremer and Dieter Nautz, May 2012

036 "Hierarchical Archimedean Copulae: The HAC Package" by Ostap Okhrin and Alexander Ristig, May 2012.

037 "Do Japanese Stock Prices Reflect Macro Fundamentals?" by Wenjuan Chen and Anton Velinov, May 2012.

038 "The Aging Investor: Insights from Neuroeconomics" by Peter N. C. Mohr and Hauke R. Heekeren, May 2012.

039 "Volatility of price indices for heterogeneous goods" by Fabian Y.R.P. Bocart and Christian M. Hafner, May 2012.

040 "Location, location, location: Extracting location value from house prices" by Jens Kolbe, Rainer Schulz, Martin Wersing and Axel Werwatz, May 2012.

041 "Multiple point hypothesis test problems and effective numbers of tests" by Thorsten Dickhaus and Jens Stange, June 2012

042 "Generated Covariates in Nonparametric Estimation: A Short Review." by Enno Mammen, Christoph Rothe, and Melanie Schienle, June 2012.

043 "The Signal of Volatility" by Till Strohsal and Enzo Weber, June 2012.

044 "Copula-Based Dynamic Conditional Correlation Multiplicative Error Processes" by Taras Bodnar and Nikolaus Hautsch, July 2012

\author{
SFB 649, Spandauer Straße 1, D-10178 Berlin \\ http:/ / sfb649.wiwi.hu-berlin.de
}




\section{SFB 649 Discussion Paper Series 2012}

For a complete list of Discussion Papers published by the SFB 649, please visit http://sfb649.wiwi.hu-berlin.de.

045 "Additive Models: Extensions and Related Models." by Enno Mammen, Byeong U. Park and Melanie Schienle, July 2012.

046 "A uniform central limit theorem and efficiency for deconvolution estimators" by Jakob Söhl and Mathias Trabs, July 2012

047 "Nonparametric Kernel Density Estimation Near the Boundary" by Peter Malec and Melanie Schienle, August 2012

048 "Yield Curve Modeling and Forecasting using Semiparametric Factor Dynamics" by Wolfgang Karl Härdle and Piotr Majer, August 2012

049 "Simultaneous test procedures in terms of p-value copulae" by Thorsten Dickhaus and Jakob Gierl, August 2012

050 "Do Natural Resource Sectors Rely Less on External Finance than Manufacturing Sectors? " by Christian Hattendorff, August 2012

051 "Using transfer entropy to measure information flows between financial markets" by Thomas Dimpfl and Franziska J. Peter, August 2012

052 "Rethinking stock market integration: Globalization, valuation and convergence" by Pui Sun Tam and Pui I Tam, August 2012

053 "Financial Network Systemic Risk Contributions" by Nikolaus Hautsch, Julia Schaumburg and Melanie Schienle, August 2012

054 "Modeling Time-Varying Dependencies between Positive-Valued HighFrequency Time Series" by Nikolaus Hautsch, Ostap Okhrin and Alexander Ristig, September 2012

055 "Consumer Standards as a Strategic Device to Mitigate Ratchet Effects in Dynamic Regulation" by Raffaele Fiocco and Roland Strausz, September 2012 